Review

\title{
State of the Art Technologies for Exoskeleton Human Lower Extremity Rehabilitation Robots
}

\author{
"Sk. Khairul Hasan and Anoop Kumar Dhingra \\ Department of Mechanical Engineering, University of Wisconsin Milwaukee, Milwaukee, WI 53211, USA
}

\author{
Article history \\ Received: 20-08-2020 \\ Revised: 29-09-2020 \\ Accepted: 30-09-2020 \\ Corresponding author: \\ S.K. Hasan \\ Department of Mechanical \\ Engineering, University of \\ Wisconsin Milwaukee, \\ Milwaukee, WI 53211, USA \\ Email: skkhasan@uwm.edu
}

\begin{abstract}
The World Health Organization reports that about 1 billion people worldwide have some form of disability. Of these, 110-190 million people have significant difficulties in functioning. Providing rehabilitation services to a large number of disabled people with limited resources is quite challenging. Robot-based neurorehabilitation is an appealing solution for providing rehabilitation services without the downside of provider fatigue. Despite the importance of robot-based rehabilitation, a limited number of resources are readily available related to the technical challenges that need to be addressed in designing human lower extremity rehabilitation robots? This paper tries to fill up the technical gaps by explaining lower extremity anatomy, probable causes of lower extremity disability, rehabilitation protocols and fundamental safety and ergonomic features that need to be considered during the design/selection of an exoskeleton robot. A comprehensive review of the state-of-the-art sensing and actuation technologies involved in human lower extremity exoskeleton robots is also presented to familiarize the reader with current technologies. It is hoped that a comprehensive coverage of all relevant anatomical, anthropometric, actuation and sensing aspects of lower extremity exoskeleton robots will help the designer come up with the best possible solution for a specific application.
\end{abstract}

Keywords: Lower Extremity Exoskeleton Robot, Rehabilitation Protocol, Lower Extremity Anatomy, Rehabilitation Robot Sensing and Actuation System

\section{Introduction}

Physical disability is defined as a physical state that influences a person's mobility, physical capacity, endurance, or dexterity. It is a severe socio-economic problem in the world. Globally, approximately $15 \%$ of the total population is considered as physically disabled. Many people experience a temporary or permanent lower or upper limb impairment sometime in their lifetime. Exoskeleton robot-based exercises are a practical approach for neurorehabilitation. Exoskeleton robots offer an array of possibilities in human upper and lower extremity rehabilitation by providing customizable physiotherapy and evaluating performance during all stages of recovery.

In recent years, research in bio-robotics has received a lot of attention because of its effectiveness in the field of upper and lower extremity rehabilitation. Exoskeleton based physical therapy, prosthetics, artificial limbs are major applications of bio-robotics. This paper focuses on Human Lower Extremity (HLE) robotic rehabilitation which has been an area of active research during the last two decades.

A number of review papers have appeared over the last five years that address different aspects of lower extremity assistive devices. Yan et al. (2015) presented a comprehensive review of all HLE assistive devices developed after the 1990s. In their review, all analyzed devices were classified based on four criteria, namely, the robot control system, mechanical structure, validation with users and classification based on mechanical structures and sensory devices.

The review article by (Rupal et al., 2016) describes the construction and technological features of existing lower extremity exoskeleton robots and classifies them based on human power amplification and rehabilitation. The existing rehabilitation devices were further classified as commercial or prototype versions. Meng et al. (2015) 
reviewed recent developments in mechanisms and control strategies for robot-assisted lower limb rehabilitation. This work addressed comprehensively various control strategies for robot-assisted human lower limb rehabilitation. Chen et al. (2016) described developments in lower extremity exoskeletons, including their structure, control algorithms used, sensing technology to determine wearer's motion intention, as well as remaining challenges in this field.

The review article by (Chen et al., 2013) focuses on lower extremity assistive robotic exoskeletons used in rehabilitation therapy. The authors classified gait rehabilitation exoskeletons into two groups: Treadmillbased gait rehabilitation exoskeletons and exoskeletons for over ground gait training/assistance. Another comprehensive review by (Shi et al., 2019) summarizes the current state-of-the-art of HLE exoskeleton robots by focusing on human gait analysis, as well as actuation system design and control of the lower extremity exoskeleton robot.

Even though the review articles mentioned above summarize the state-of-the-art for HLE robots, it is seen that a majority of these articles have focused on an overall description of the robot, mechanism and control strategies, application (power assist or rehabilitation) and commercial aspects. Design considerations for these robots which are based on HLE anatomy, training methods and the state-ofthe-art in sensing and actuation technologies have received limited attention in these works. To overcome these gaps in the literature, this review article addresses probable causes of HLE disability, rehabilitation protocol, lower extremity anatomy and basic safety and ergonomic design requirements that need to be considered during design/selection of an exoskeleton robot. A comprehensive review of the state-of-the-art sensing and actuation technologies is also presented to familiarize the readers with current technologies.

This paper is divided into nine sections. Section two discusses human lower extremity anatomy. An understanding of the lower extremity anatomy is important in understanding the causes of lower extremity disabilities and to design a suitable lower extremity assistive device. Section three describes the probable causes of human lower extremity disabilities. Fundamental safety and ergonomic features requirements for rehabilitation robots are discussed in section four. Section five describes the robot-assisted training methods, including active, passive, active assist and active resist forms of physiotherapy. Section six presents a review of existing exoskeleton robots. It includes a classification of existing 25 exoskeleton robots based on robot's Degrees of Freedom (DoF), actuator type, mechanical power transmission, feedback sensing method and control algorithm used. Sections seven and eight deal with actuators, drive systems and mechanical power transmission systems respectively. Lastly, section nine describes the intention sensing system that helps the user interact with the robot.

\section{Human Lower Extremity Anatomy}

Knowledge of HLE anatomy is essential to understanding the causes of lower extremity disability, developing a suitable rehabilitation protocol and designing an exoskeleton robot for HLE rehabilitation. Extracting features from the HLE anatomy serves as a starting point for an ergonomic exoskeleton rehabilitation robot. For designing, developing and performance evaluation of a HLE exoskeleton robot, the following information is needed: The structure of bones and joints, nervous system, muscle map for HLE, degrees of freedom, ranges of motion and anthropometric parameters. These aspects are discussed briefly in the next couple of subsections.

\section{Bones and Joints}

The HLE consists of three major segments: Thigh, shank and foot. Figure 1 shows the major bones and joints present in the HLE. The thigh connects with the vertebra (pelvis bone) through the hip joint, the shank connects with the thigh at the knee joint and the foot is attached to the shank at the ankle joint. The femur, the longest and heaviest bone in the human body, is located in the thigh segment. The shank consists of two parallel bones, the tibia and the fibula. Tibia is located on the medial side and fibula is located on the lateral side of the body. The foot consists of a total of 26 bones. The two significant bones in the foot are the talus and calcaneus. Tibia and fibula connect with the talus. Calcaneus is the largest bone in the foot joint and produces cushioned action during human movement. Figure 2 shows the ankle joint and bones in the foot.

\section{Nervous System}

The human body's nervous system is similar to the electrical wiring in a robot. It is a collection of different types of nerves that are made of neurons. There are two types of neurons: Sensory neurons and motor neurons. The role of the nervous system is to communicate between the Central Nervous System (CNS) and different parts of the body. Typically, it takes a fraction of a millisecond to transfer signals between two points. The complete nervous system divided into two parts, the CNS and the Peripheral Nervous System (PNS). Figure 3 shows the central and peripheral nervous systems of the body. The brain, spinal cord and retina of the eye together comprise the central nervous system, which works as the main controller of the body. The PNS communicates between the CNS and different parts of the body. The sensory nerves carry stimuli signals from different receptors of sensory organs to the brain, whereas the motor nerves carry activation signals from the brain to various muscles and glands. 


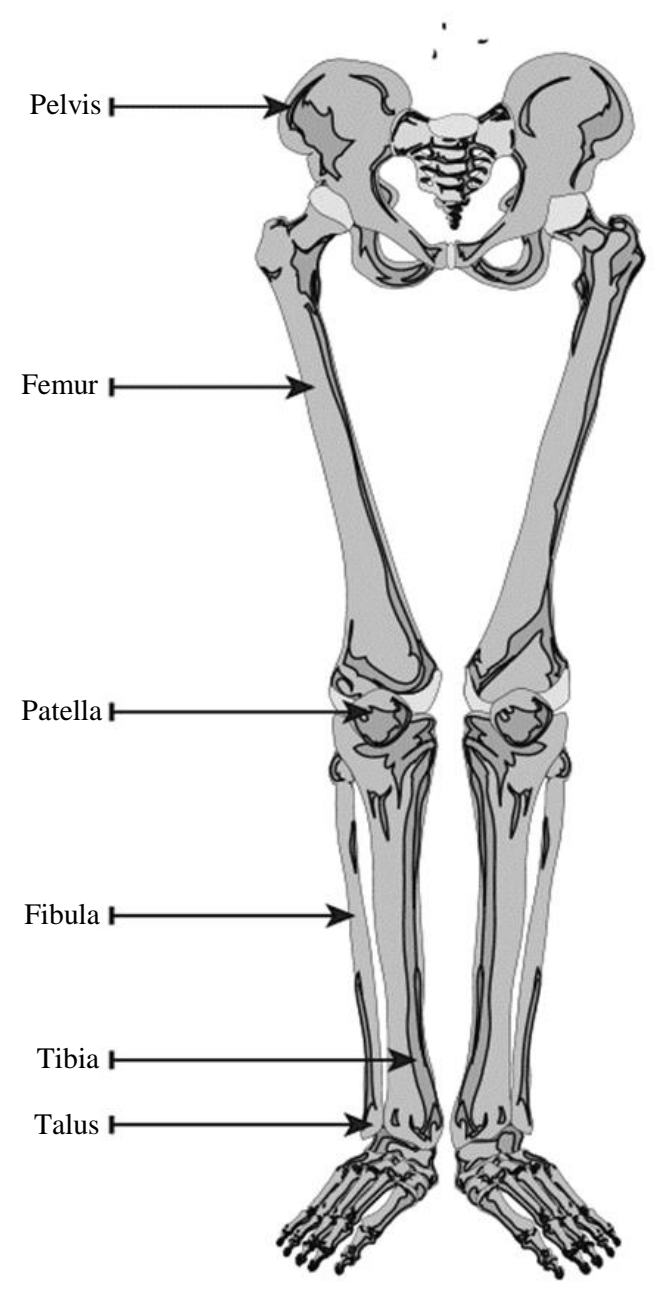

Fig. 1: Human lower extremity bones

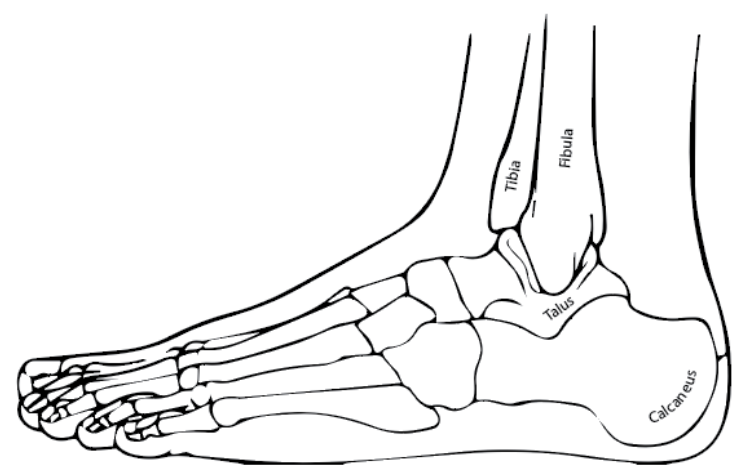

Fig. 2: Bones of the ankle joint and foot

Patients with nerve impairment may suffer from epilepsy, multiple sclerosis, amyotrophic lateral sclerosis, Huntington's disease, Alzheimer's disease, etc. The nervous system may also be affected by vascular disorders. Nervous system disorders may lead to upper or lower extremity disabilities.

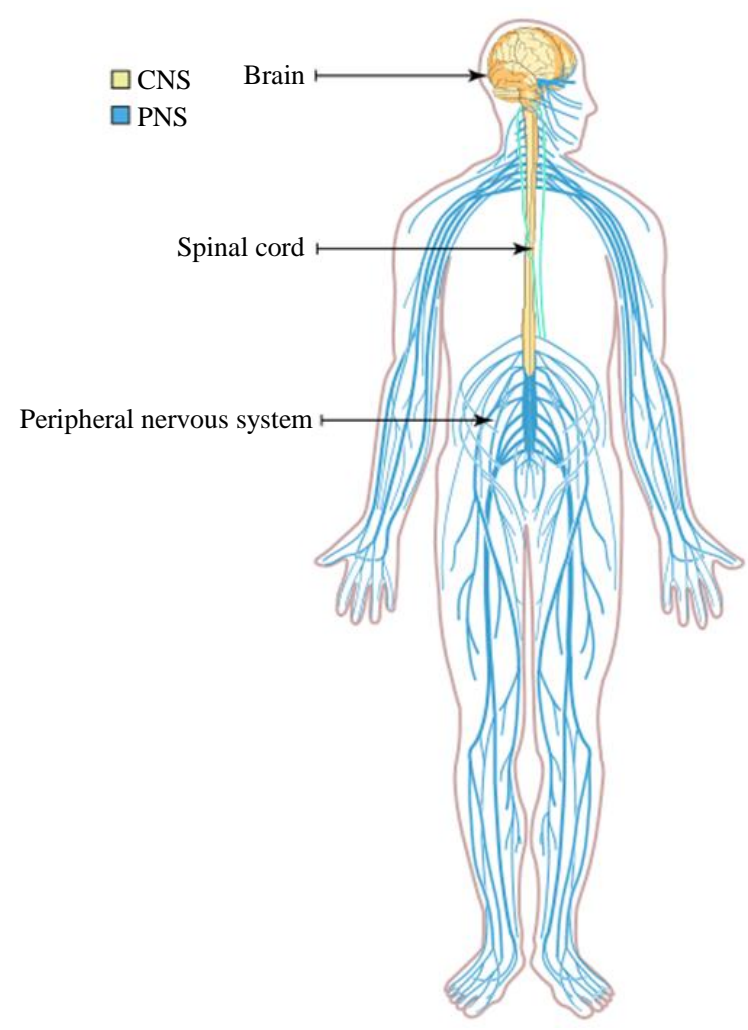

Fig. 3: Human body central and peripheral nervous system

\section{Muscles}

The muscles act similar to linear actuators and are made of soft tissue. The muscle cells consist of two protein filaments, actin and myosin, which can slide with respect to each other. The sliding of actin and myosin layers produces contraction that changes both the length and shape of the cell. Muscles produce forces and motion and are responsible for posture, locomotion and the movements of the internal organs. There are three types of muscles: Skeletal muscles, smooth muscles and cardiac muscles.

A skeletal muscle, also known as voluntary muscle, is attached to the bone by tendons and works for skeletal movements. Although postural control is often done by unconscious reflex, skeletal muscles are responsible for conscious control. Muscles receive actuation command from the brain via the motor neurons. To diagnose a lower extremity movement disorder, knowledge of muscle location and their contribution to different movements is needed. A list of all skeletal muscles involved in HLE movements is given in Fig. 4 to 6 . Table 1 presents the human lower extremity DOF and their corresponding muscles. For examining the muscle's health, its activation level and the function of the corresponding nerves, muscle tone is measured using surface electromyography. For 
proper placement of surface electromyography electrodes, the muscles need to be identified at their exact locations. Muscle activation levels can be used for triggering an active type of physical therapy.

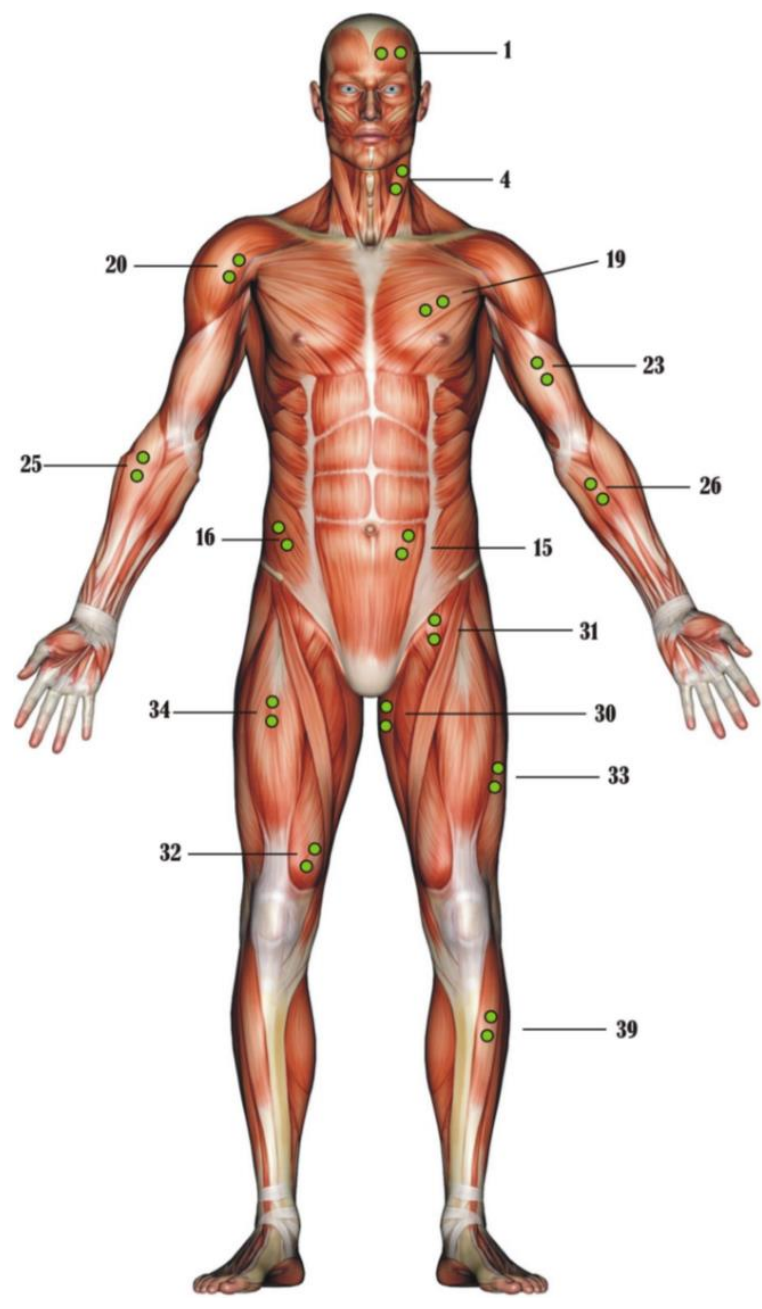
\# Muscle name
1. Frontalis
2. Temporalis
3. Masseter
4. Sternocleidomastoid (SCM)
5. C4 Cervical Paraspinals (CP)
6. Upper Trapezius
7. Lower Trapezius
8. Infraspinatus
9. Latissimus Dorsi
10. T2 Paraspinals
11. T8 Paraspinals
12. T10 Paraspinals
13. L1 Paraspinals
14. L5 Paraspinals
15. Rectus Abdominal
16. Abdominal Oblique
17. Internal Oblique
18. Serratus Anterior
19. Pectoralis Major
20. Anterior Deltoid
21. Lateral Deltoid
22. Posterior Deltoid
23. Biceps Brachii
24. Triceps Branchii
25. Brachioradialis
26. Wrist Flexor
27. Wrist Extensor
28. Gluteus Medius
29. Gluteus Maximus
30. Hip Adductor
31. Hip Flexor
32. Vastus Medialis Oblique (VMO)
33. Vastus Lateralis (VL)
34. Quadriceps Femoris
35. Medial Hamstring
36. Medial Gastrocnemius
37. Lateral Gastrocnemius
38. Soleus
39. Tibialis Anterior

Fig. 4: Frontal view of the human muscular system (Florimond, 2008) 


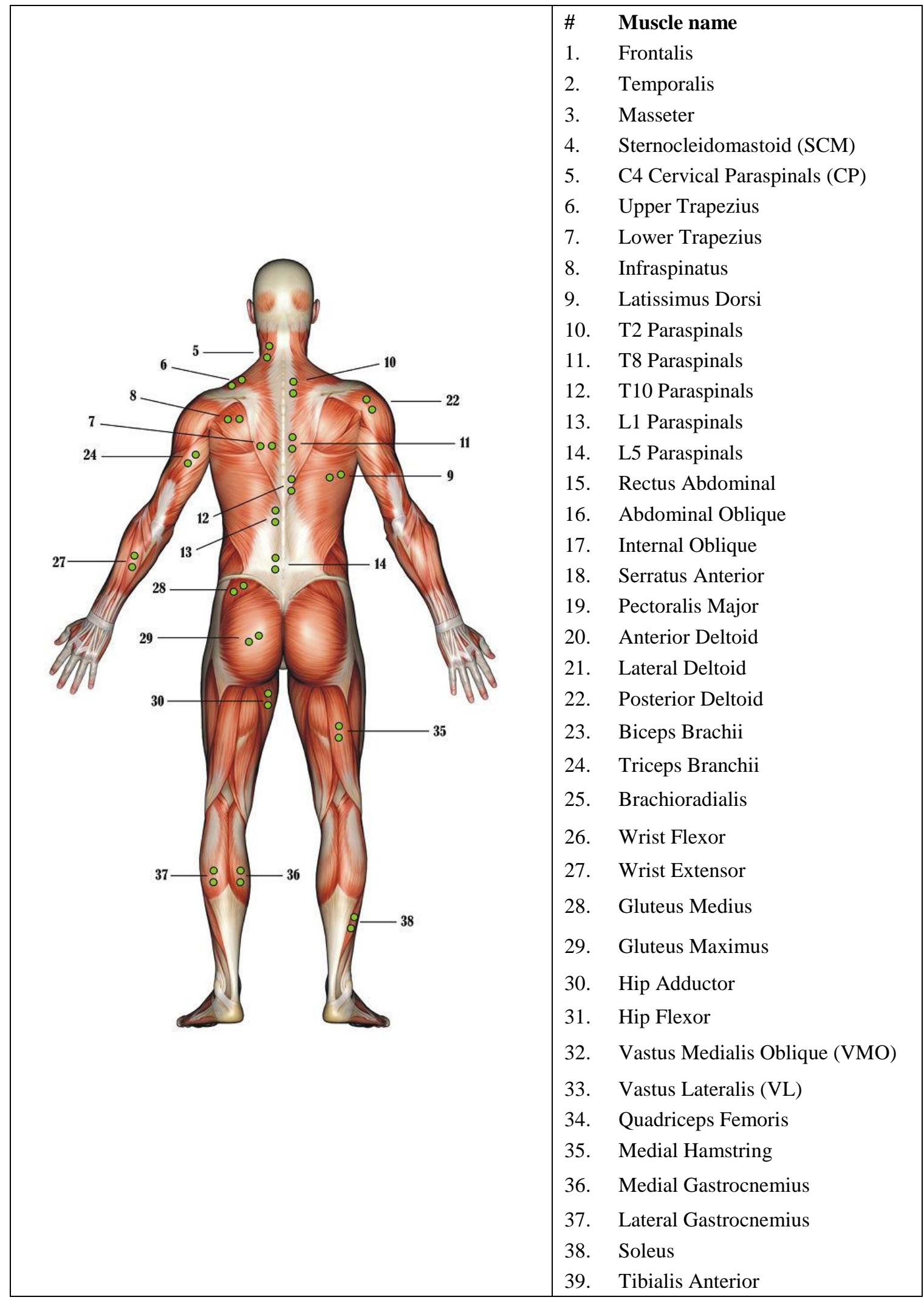

Fig. 5: Rear view of the human muscular system (Florimond, 2008) 


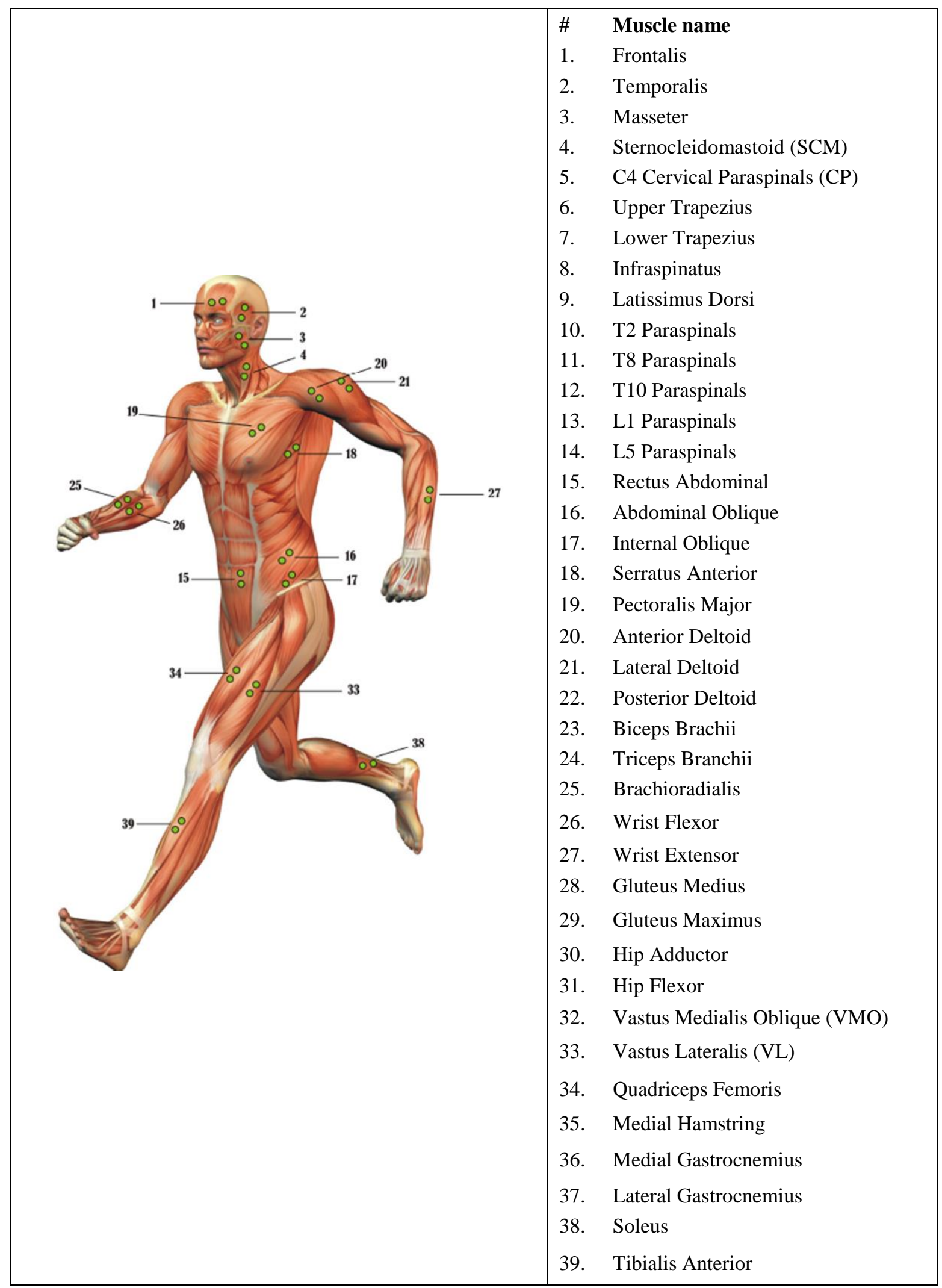

Fig. 6: Lateral view of the human muscular system (Florimond, 2008) 
Table 1: List of human lower extremity DoF and their corresponding muscles (Florimond, 2008)

\begin{tabular}{|c|c|c|}
\hline Movement & Hip flexion & Hip extension \\
\hline Muscles Involved & $\begin{array}{l}\text { Adductor brevis, Adductor longus, Iliacus, Pectineus, } \\
\text { Psoas major, Rectus femoris, Sartorius, Tensor Fascia latae }\end{array}$ & $\begin{array}{l}\text { Adductor magnus, Biceps femoris, Gluteus } \\
\text { maximus, Semimem branosus, Semitendinosus }\end{array}$ \\
\hline Movement & Hip Abduction & Hip Adduction \\
\hline Muscles Involved & $\begin{array}{l}\text { Gemellus inferior, Gemellus superior, Gluteus maximus, } \\
\text { Gluteus medius, Gluteus minimus, Piriformis, Tensor fascia } \\
\text { latae }\end{array}$ & $\begin{array}{l}\text { Adductor brevis, Adductor longus, Adductor magnus, } \\
\text { Biceps femoris, Gluteus maximus, Gracilis, Pectineus, } \\
\text { Psoas major }\end{array}$ \\
\hline Movement & Hip Medial Rotation & Hip Lateral Rotation \\
\hline Muscles Involved & Gluteus medius, Gluteus minimus, Tensor fascia latae & $\begin{array}{l}\text { Adductor brevis, Adductor longus, Adductor magnus, } \\
\text { Biceps femoris, Gemellus inferior, Gemellus superior, } \\
\text { Gluteus maximus, Gluteus medius, Obturator externus, } \\
\text { Obturator internus, Piriformis } \\
\text { Quadratus femoris, Sartorius }\end{array}$ \\
\hline Movement & Knee Flexion & Keen Extension \\
\hline Muscles Involved & $\begin{array}{l}\text { Biceps femoris, Gastrocnemius } \\
\text { Gracilis, Popliteus, Sartorius, } \\
\text { Semimembranosus, Semitendinorus }\end{array}$ & $\begin{array}{l}\text { Rectus femoris, Tensor Fascia latae, Vastus intermedius, } \\
\text { Vastus lateralis, Vastus medialis }\end{array}$ \\
\hline Movement & Shank Medial Rotation & Shank Lateral Rotation \\
\hline Muscles Involved & $\begin{array}{l}\text { Gracilis, Popliteus, Sartorius, Semimembranosus, } \\
\text { Semitendinorus }\end{array}$ & Biceps femoris \\
\hline Movement & Ankle Dorsiflexion & Ankle Plantarflexion \\
\hline Muscles Involved & $\begin{array}{l}\text { Extensor digitorum longus, Extensor hallucis longus, } \\
\text { Peroneus tertius, Tibialis anterior }\end{array}$ & $\begin{array}{l}\text { Flexor digitorium longus, Flexor hallucis longus, } \\
\text { Gastrocnemius, Peroneus brevis, Peroneus longus, } \\
\text { Plantaris, Soleus, Tibialis posterior }\end{array}$ \\
\hline Movement & Ankle Eversion/Supination & Ankle Inversion/Pronation \\
\hline Muscles Involved & $\begin{array}{l}\text { Extensor digitorum longus, Peroneus brevis, Peroneus } \\
\text { longus, Peroneus tertius }\end{array}$ & $\begin{array}{l}\text { Flexor digitorum longus, Tibialis anterior, Tibialis } \\
\text { posterior }\end{array}$ \\
\hline
\end{tabular}

A smooth muscle, also known as an involuntary muscle, forms the walls of the organs such as the stomach, intestine, bronchi, uterus, bladder, blood vessels, etc. Smooth muscles are not under conscious control. Finally, the cardiac muscle is an "involuntary muscle," structurally similar to the skeletal muscle and is found only in the heart.

\section{Human Lower Extremity Degrees of Freedom}

The HLE has a total of 7 DoF. The femur attaches to the pelvis through a ball socket joint (Fig. 7) that allows it to rotate along 3 individual axes which allow for:

1. Hip abduction adduction

2. Hip flexion-extension

3. Hip internal and external rotation

At the knee joint, the femur connects with the tibia and fibula via an elliptical-shaped end called femoral condyle. Russell et al. (2018) presented the shape and size of the femoral condyle with its instantaneous center of rotation. As the connection surface has an elliptical shape, it allows for rotational as well as linear displacement at the knee joint. The leg length increases during flexion and decreases during extension (Hasan and Dhingra, 2020). Figure 8 shows all seven DoF of the HLE.

The knee joint provides 3 DOFs:

\section{Knee flexion and extension}

2. Knee linear displacement (passive DoF due to elliptical condyle end)

3. Shank internal and external rotation

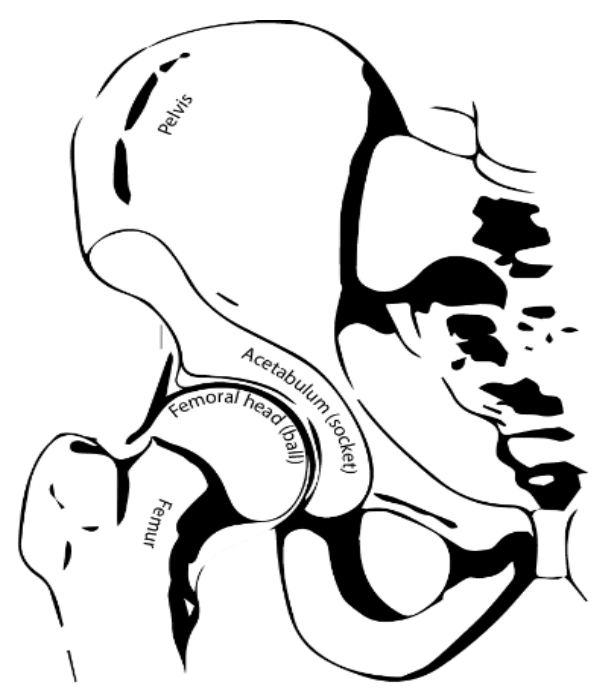

Fig. 7: Hip ball socket joint

The tibia and fibula are attached to the talus at their lower ends that provide 2 DOF. The allowed motions are:

1. Ankle flexion-extension

2. Ankle pronation and supination 


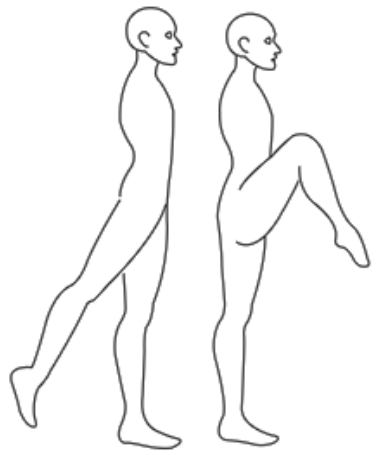

Hip flexion | Hip extension

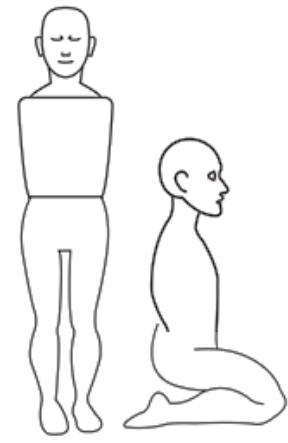

Knee flexion | Knee extension

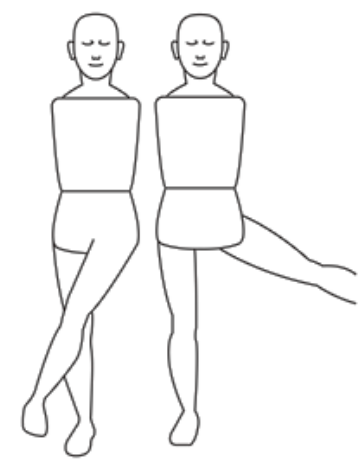

Hip adduction | Hip Abduction

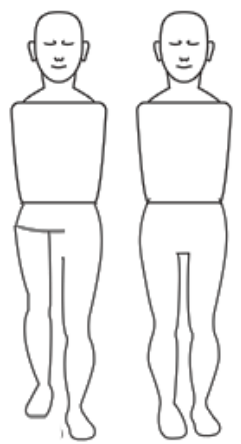

Shank internal rotation | Shank external rotation

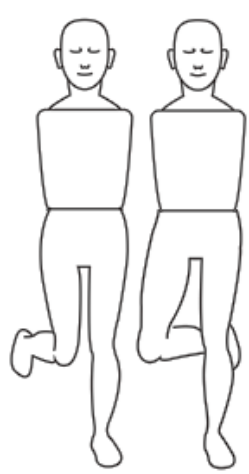

Hip internal rotation | Hip external rotation

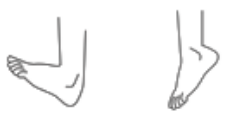

Ankle flexion | Ankle extension
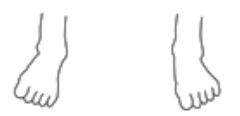

Ankle pronation | Ankle supination

Fig. 8: Human Lower extremities degrees of freedom

Table 2: Human lower extremity ranges of motion

\begin{tabular}{|c|c|c|c|c|c|}
\hline Joint & Movement & $\begin{array}{l}\text { American Academy of } \\
\text { Orthopedic Surgeons (1965) }\end{array}$ & $\begin{array}{l}\text { Kendall et al. } \\
(2005)\end{array}$ & $\begin{array}{l}\text { American Medical } \\
\text { Association }\end{array}$ & Kurz (2015) \\
\hline \multirow[t]{6}{*}{ Hip } & Flexion & $0-120^{\circ}$ & $0-125^{\circ}$ & $0-100^{\circ}$ & $0-130^{\circ}$ \\
\hline & Extension & $0-30^{\circ}$ & $0-10^{\circ}$ & $0-30^{\circ}$ & $0-30^{\circ}$ \\
\hline & Abduction & $0-45^{\circ}$ & $0-45^{\circ}$ & $0-40^{\circ}$ & $0-50^{\circ}$ \\
\hline & Adduction & $0-30^{\circ}$ & $0-10^{\circ}$ & $0-20^{\circ}$ & $0-30^{\circ}$ \\
\hline & Internal Rotation & $0-45^{\circ}$ & $0-45^{\circ}$ & $0-40^{\circ}$ & $0-40^{\circ}$ \\
\hline & External Rotation & $0-45^{\circ}$ & $0-45^{\circ}$ & $0-50^{\circ}$ & $0-45^{\circ}$ \\
\hline \multirow[t]{4}{*}{ Knee } & Flexion & $0-135^{\circ}$ & $0-140^{\circ}$ & $0-150^{\circ}$ & $0-130^{\circ}$ \\
\hline & Extension & - & - & - & $0-15^{\circ}$ \\
\hline & Internal Rotation & - & - & - & $0-10^{\circ}$ \\
\hline & External Rotation & - & - & - & $0^{\circ}$ \\
\hline \multirow[t]{4}{*}{ Ankle } & Dorsiflexion & $0-20^{\circ}$ & $0-20^{\circ}$ & $0-20^{\circ}$ & $0-20^{\circ}$ \\
\hline & Plantar flexion & $0-50^{\circ}$ & $0-45^{\circ}$ & $0-40^{\circ}$ & $0-45^{\circ}$ \\
\hline & Inversion/Pronation & $0-35^{\circ}$ & $0-35^{\circ}$ & $0-30^{\circ}$ & $0-30^{\circ}$ \\
\hline & Eversion/Supination & $0-15^{\circ}$ & $0-20^{\circ}$ & $0-20^{\circ}$ & $0-20^{\circ}$ \\
\hline
\end{tabular}

\section{Range of Motion}

Maintaining a proper Range of Motion (RoM) is essential for the exoskeleton robot. Most healthy people have a similar range of motion. In the case of physical therapy, the RoM varies with the patient's health condition. A failure to meet this criterion may result in serious adverse consequences. The reported HLE ranges of motion from various sources are given in Table 2 .

\section{Anthropometric Parameters}

Anthropometrical properties play an essential role in the development of human lower extremity kinematic and dynamic models. Nikolova and Toshev (2008) reported the anthropometrical properties based on the data collected from 5290 individuals (2435 males and 2855 females).

Some empirical equations are also available in the literature to determine lower extremity anthropometrical 
parameters based on the weight and height of the subject (Contini, 1972). Equation (1)-(21) are a set of empirical equations that can be used for calculating human lower extremity anthropometrical parameters based on the subject's weight and height:

$$
B_{d}=0.6905+0.0297 C \frac{l b}{f t^{3}}, \text { where } C=H W^{-\frac{1}{3}},
$$

In Equation (1) $B_{d}$ is the body density $\left(l b s / f t^{3}\right), H$ is the height of the subject (inch), $W$ is the body weight of the subject $(l b s)$. The thigh, shank and foot densities are determined as follows,

$$
\begin{aligned}
& T_{d}=1.035+0.814 * B_{d} \frac{l b}{f t^{3}} \\
& S_{d}=1.065+B_{d} \frac{l b}{f t^{3}} \\
& F_{d}=1.071+B_{d} \frac{l b}{f t^{3}}
\end{aligned}
$$

In Equation (2)-(4), $T_{d}$ is the thigh density, $S_{d}$ is the shank density and $F_{d}$ is the foot density.

The whole body volume $\left(B_{v}\right)$ is calculated using the body weight and body density

$$
B_{v}=\frac{W}{B_{d}} f t^{3}
$$

The volumes of thigh, shank and foot were calculated as follows:

$$
\begin{aligned}
& T_{v}=0.0922 * B_{v} f t^{3} \\
& S_{v}=0.0464 * B_{v} f t^{3} \\
& F_{v}=0.0124 * B_{v} f t^{3}
\end{aligned}
$$

Approximate weights of the thigh, shank and foot were calculated as given in Equation (9)-(11):

$$
\begin{aligned}
& T_{m}=T_{v} * T_{d} l b s \\
& S_{m}=S_{v} * S_{d} l b s \\
& F_{m}=F_{v} * F_{d} l b s
\end{aligned}
$$

The length of the thigh $\left(T_{l}\right)$, shank $\left(S_{l}\right)$, foot $\left(F_{l}\right)$ and ankle to lower face of the foot $\left(A_{g}\right)$ were calculated as shown in Equation (12)-(15):

$$
\begin{aligned}
& T_{l}=0.245 * H \text { inch }, \\
& S_{l}=0.285 * H \text { inch },
\end{aligned}
$$

$F_{l}=0.152 * H$ inch,

$A_{g}=0.043 * H$ inch

The locations of the center of the mass from the proximal joint for the thigh $\left(T_{c m}\right)$, shank $\left(S_{c m}\right)$, foot $\left(F_{c m}\right)$ are given by Equation (16)-(18):

$$
\begin{aligned}
& T_{c m}=0.41 * T_{l} \text { inch }, \\
& S_{c m}=0.393 * S_{l} \text { inch, } \\
& F_{c m}=0.445 * F_{l} \text { inch }
\end{aligned}
$$

The empirical equations for the inertial properties of the thigh $T_{i}$, shank $S_{i}$ and foot $F_{i}$ are given in Equation (19)-(21):

$T_{i}=\left[\begin{array}{ccc}T_{m}\left(0.124 * T_{l}\right)^{2} & 0 & 0 \\ 0 & T_{m}\left(0.267 * T_{l}\right)^{2} & 0 \\ 0 & 0 & T_{m}\left(0.267 * T_{l}\right)^{2}\end{array}\right]$

$S_{i}=\left[\begin{array}{ccc}S_{m}\left(0.281 * S_{l}\right)^{2} & 0 & 0 \\ 0 & S_{m}\left(0.114 * S_{l}\right)^{2} & 0 \\ 0 & 0 & S_{m}\left(0.275 * S_{l}\right)^{2}\end{array}\right]$

$$
F_{i}=\left[\begin{array}{ccc}
F_{m}\left(0.124 * F_{l}\right)^{2} & 0 & 0 \\
0 & F_{m}\left(0.245 * F_{l}\right)^{2} & 0 \\
0 & 0 & F_{m}\left(0.257 * F_{l}\right)^{2}
\end{array}\right]
$$

\section{Probable Causes of Physical Disability}

The reasons behind physical disability can be classified into two categories: Hereditary/congenital or acquired. Congenital disability occurs before or during birth whereas acquired disability may appear at any moment during the lifetime. Congenital forms of disability are hard to overcome using physical therapy.

There are multiple causes for the acquired type of physical disability. Any kind of injury/damage in the nervous system may lead to acquired physical disability. These injuries may include injuries in the central nervous system (brain, spinal cord) or the peripheral nervous system. The primary causes that damage the central nervous system include accidental brain injuries, strokes, trauma, infections, insufficient oxygen supply to the brain cells, etc.

Stroke is a common cause of neurological injuries which often paralyzes one or more limbs of the body. 
Physical therapy is the only treatment for post-stroke recovery (Gibson, 1990). Epilepsy, an abnormal electrical activity of the brain, causes short term or long-term physical disability (Brodie et al., 2012). Cerebral palsy is due to brain cell damage or malformation, which affects a person's movements and leads to physical disability. Cerebral palsy occurs during birth (due to obstructive labor), but the symptoms appear during early childhood (Harstad and Albers-Prock, 2011). Multiple sclerosis is an unpredictable disorder of the central nervous system, which freezes communication between the central nervous system and the peripheral nervous system (Waksman, 2020). Muscular dystrophy weakens the muscles; as a result, physical disability appears (Bushby and Marini-Bettolo, 2020).

Any type of fall that causes injuries to the central nervous system or peripheral nervous system also leads to long or short-term physical disability. Fall also causes fracture of the bones and often requires surgery; after surgery, the patient needs physical therapy to improve mobility disorders. Thus, any type of injury that disrupts communication between the CNS and PNS causes disability.

\section{Requirements for Exoskeleton Rehabilitation Robot}

Specific safety standards should be maintained for HLE exoskeleton robots to protect the user from any dangers. By following ergonomic design rules, both the user's comfort and the physiotherapy performance can be improved. The next two subsections briefly explain the desirable safety and ergonomic design features that need to be considered while designing an exoskeleton robot.

\section{Safety}

Safety is the most critical requirement for an exoskeleton or wearable robot. Exoskeleton robot interacts very closely with the human body. Any runtime failure in mechanical, electrical and electronics, or control algorithms may cause serious adverse consequences. Rehabilitation exoskeleton robot works parallel with the human joints with a corresponding range of motion for every joint. For healthy subjects, the RoMs have some standard values, whereas the RoM for impaired people are different, depending on the severity of impairment. Every exoskeleton robot should have a mechanism to limit the RoM of the joints. It may be in the form of a mechanical stopper or an electromechanical sensor-based stopping system. Further, every exoskeleton robot should also be equipped with an easily accessible emergency stop button. The function of the emergency stop button would be to stop the movement immediately and hold the robot against gravity.

Exoskeleton robots are designed by considering a maximum payload and exceeding the maximum limit may cause electrical or mechanical failures. A higher safety factor can reduce the chances of both electrical and mechanical failures. Robot payload specifications should be very clearly mentioned in the robot's user manual.

The robot should be operated at a low voltage to minimize the risk of electrocution. The severity of the electrical injuries depends on the amount of current flowing through the human body. The skin resistance varies with sweat gland activities and body temperature. Based on ohm's law, lower skin resistance allows more current flow through the body. While skin resistance is variable, the risk of electrocution can be reduced by avoiding higher operating voltages in a robot.

During the mechanical design of the robot, special attention should be given to avoid sharp edges and corners, which increase the risk of injuries. Dangling wires on moving parts increase the risk of an accident. The designer should allow a suitable passage for electrical wiring.

\section{Ergonomic Mechanical Design}

The utilization of ergonomic design rules improves the effectiveness of the rehabilitation exoskeleton robot. Since the exoskeleton robot is attached firmly to the wearer's body, an ergonomic design can improve the user's comfort and allow the user to exercise for a longer duration. The major focus of applying ergonomic design rules in rehabilitation exoskeleton robots are to minimize the macro and micro misalignments. The robot's axes of rotation should be closely aligned with the user's joint axes of rotation. Exoskeleton robots with anthropomorphic structures help to improve joint axes alignment (Cenciarini and Dollar, 2011). Careful consideration of all DoF helps to make the exoskeleton robot ergonomic. For instance, the knee joint is elliptical, which provides both rotational and linear movements to occur simultaneously. None of the existing 25 lower extremity exoskeletons reviewed in section 6 consider the linear motion of the knee; this affects the user's comfort and puts extra pressure on the knee joint during exercise (Hasan and Dhingra, 2020). The robot trajectories should be based on natural human movements. A lot of researchers have developed natural trajectories based on the data collected from healthy subjects (Jezernik et al., 2003; Neuhaus et al., 2011; Kwa et al., 2009; Farris et al., 2013).

\section{Robot-Assisted Training Methods}

The effectiveness of the physical therapy depends on delivering the right form of exercise to the patient, at the right stage of recovery. It depends entirely on the competence of the caregiver. Currently, based on the patient's health condition and recovery stage, the therapist selects the proper form of physiotherapy. The primary role of the robot is to follow the therapist's command and perform a task repetitively. It is expected that in the near future with the help of artificial intelligence and natural language processing, the robot will be able to select the appropriate exercise(s) based on the patient's symptoms. 
The conventional physical therapy-based recovery process consists of three stages: Primary, intermediate and advanced stage. During the primary stage, the therapist moves the limb along a specific trajectory to improve the joint's range of motion, blood circulation and reduce disuse atrophy. In the robotic rehabilitation system, the robot does the same thing. This mode of therapy is also referred to as passive form of physical therapy. During the intermediate stage of physiotherapy, the subject is also engaged in the exercise. During conventional physical therapy, the patient is asked to move a limb voluntarily. But in the robot-based physical therapy called the active form of physical therapy, the robot moves the limb along a trajectory based on the user's intentions. In the active assist form of physical therapy, the subject is asked to move voluntarily. If the subject fails to complete the task based on specific criteria, the robot will assist in completing the task. The final stage of physical therapy is active resist form of exercise. Some resistive force is applied to the limb and the patient needs to work against the resistive force. The active resist form of exercise helps to increase muscle strength. Most of the time, viscous friction is applied to the joint to create specific resistive forces. During robot assistive physiotherapy, a physiotherapist may be present in person or may use haptic technology. Table 3 summarizes different forms of robot assistive exercises, their expected outcome along with representative research works.

\section{Review of Existing Human Lower Extremity Exoskeleton Robots}

During the last two decades, significant advances have been made in establishing robot-assisted physical therapies. The major advantage of robot-based physical therapy is that the robot can efficiently provide passive or active forms of physical therapy without the downside of provider fatigue. The patients can receive therapeutic exercises based on their schedule. The performance evaluation is easier and accurate compared to conventional forms of physical therapy.
Based on our literature search, 25 rehabilitation robots were identified that are used to assist patients with lower extremity disorders. Some robots are specific to gait pattern rehabilitation whereas some are more focused on active or passive forms of robot-assisted physical exercises. In this study, the focus is on the sensing and actuation mechanism used for existing robots. Table 4 enumerates existing rehabilitation robots along with their DoF, actuator type, mechanical power transmission, feedback sensing method and control algorithms.

The existing HLE rehabilitation robots can be classified in many ways based on purpose of the device, actuation system, control scheme used, type of exercise provided by the robot, the sensing method used, etc. Figure 9 illustrates the classification criteria for existing human lower extremity rehabilitation robots.

The next section discusses the actuators and drive system principles along with representative works.

\section{Actuators and Drive System}

Actuator selection and placement plays a vital role in the robotic system. Based on the working principle, an actuator can be active or passive. The actuator is selected based on the peak torque and power requirements during dynamic simulation which in turn depends on the input trajectory, the robot's shape, size and payload considered during the simulation. Based on the application requirements, an actuator can be electric, hydraulic, pneumatic, or hybrid type. The robot's mechanical structure also has a strong influence on the actuator's shape and size. The power requirement of the actuator is proportional to the robot's bandwidth (maximum range of operating frequency). Higher bandwidth robots require more powerful actuators. The efficiency and total power consumption of a robot largely depends on the actuator's characteristics. In the case of robots with electric actuators, the power transmission wire gauge depends on the actuator's specifications. For a specific power, the higher the actuator's operating voltage, the lower are the current requirements, with a corresponding influence on the wire gauge. A proper selection of actuators increases the power-weight ratio.

Table 3: Different forms of physical therapy, their expected outcome and representative work

\begin{tabular}{|c|c|c|c|}
\hline Control modes & Description & Expected outcomes & Representative works \\
\hline Passive mode & $\begin{array}{l}\text { Robot helps the patient by performing } \\
\text { passive exercises repeatedly along the } \\
\text { predefined trajectories }\end{array}$ & $\begin{array}{l}\text { Helps in motor function recovery, } \\
\text { reduce muscle disuse atrophy by } \\
\text { repetitive exercises }\end{array}$ & $\begin{array}{l}\text { Veneman et al. (2007a; } \\
\text { Colombo et al., 2001; Zeilig et al., } \\
\text { 2012; Esquenazi et al., 2012) }\end{array}$ \\
\hline Active mode & $\begin{array}{l}\text { Robot helps patients for the voluntary } \\
\text { movement. Mainly move the joints based } \\
\text { on the user intentions }\end{array}$ & $\begin{array}{l}\text { Helps in motor learning, engage } \\
\text { patient into the exercise process }\end{array}$ & $\begin{array}{l}\text { Kawamoto et al. (2009; } \\
\text { Kawamoto and Sankai, 2004; } \\
\text { Veneman et al., 2007a; Suzuki et al., } \\
\text { 2005; Wang et al., 2013) }\end{array}$ \\
\hline Active assist mode & $\begin{array}{l}\text { Robot helps patient's voluntary } \\
\text { movement; if the user fails to meet specific } \\
\text { criteria, the robot helps to complete it }\end{array}$ & $\begin{array}{l}\text { Helps in motor learning, improving } \\
\text { confidence via guided process }\end{array}$ & Veneman et al., (2007a) \\
\hline Active resist mode & $\begin{array}{l}\text { It is similar to active mode. The robot } \\
\text { provides resistive force as a challenge } \\
\text { to the patient. }\end{array}$ & $\begin{array}{l}\text { Helps to strengths muscles, suitable } \\
\text { for the final recovery phases }\end{array}$ & $\begin{array}{l}\text { Lam et al. }(2011 ; \\
\text { Kawamoto et al., 2010) }\end{array}$ \\
\hline
\end{tabular}


Sk. Khairul Hasan and Anoop Kumar Dhingra / Journal of Mechatronics and Robotics 2020, Volume 4: 211.235 10.3844/jmrsp.2020.211.235

Table 4: List of existing rehabilitation robot along with their DoF, actuator type, mechanical power transmission, feedback sensing method and control algorithms

\begin{tabular}{|c|c|c|c|c|c|c|c|}
\hline \# & Device name & $\begin{array}{l}\text { Degrees of } \\
\text { freedom }\end{array}$ & Actuator type & $\begin{array}{l}\text { Mechanical power } \\
\text { transmission method }\end{array}$ & $\begin{array}{l}\text { Feedback/ } \\
\text { intention sensing } \\
\text { method }\end{array}$ & Control algorithm & Ref. \\
\hline 1. & $\begin{array}{l}\text { EXPOS and } \\
\text { SUBAR }\end{array}$ & $\begin{array}{l}\text { Hip: F-E (A) } \\
\text { Knee: F-E (A) } \\
\text { Ankle: (U) } \\
\text { Double legs }\end{array}$ & DC motor & $\begin{array}{l}\text { Mechanical Gearbox, } \\
\text { Cable pulley system }\end{array}$ & Force sensors & $\begin{array}{l}\text { Fuzzy logic control, } \\
\text { Impedance control }\end{array}$ & $\begin{array}{l}\text { Kong and Jeon } \\
\text { (2006) }\end{array}$ \\
\hline 2. & Lokomoat & $\begin{array}{l}\text { Pelvis: VM (U) } \\
\text { Hip: F-E (A) } \\
\text { Knee: F-E (A) } \\
\text { Ankle: F-E (U) } \\
\text { Double legs }\end{array}$ & DC motor & $\begin{array}{l}\text { Ball screw } \\
\text { mechanism }\end{array}$ & $\begin{array}{l}\text { Goniometer, } \\
\text { force sensor }\end{array}$ & $\begin{array}{l}\text { Hybrid force- } \\
\text { position control }\end{array}$ & $\begin{array}{l}\text { Colombo et al. } \\
\text { (2000; } \\
\text { Bernhardt et al., } \\
\text { 2005) }\end{array}$ \\
\hline 3. & Lopes & $\begin{array}{l}\text { Hip: F-E } \\
\text { A-A (A) } \\
\text { Knee: F-E (A) } \\
\text { Double legs }\end{array}$ & SEA & Bowden-cable based & $\begin{array}{l}\text { Spring-based } \\
\text { passive force } \\
\text { sensor }\end{array}$ & Impedance control & $\begin{array}{l}\text { Veneman et al., } \\
\text { (2007a; 2005) }\end{array}$ \\
\hline 4. & ALEX & $\begin{array}{l}\text { Trunk: } 4 \text { DOF } \\
\text { Hip: F-E (A), A-A } \\
\text { Knee: F-E (A) } \\
\text { Ankle: F-E } \\
\text { Single leg }\end{array}$ & $\begin{array}{l}\text { Linear Actuator, } \\
\text { Spring as a } \\
\text { passive actuator }\end{array}$ & Mechanical linkage & $\begin{array}{l}\text { Force and torque } \\
\text { sensor }\end{array}$ & $\begin{array}{l}\text { Force, impedance } \\
\text { control }\end{array}$ & $\begin{array}{l}\text { Banala et al. (2007; } \\
\text { Agrawal et al., 2007; } \\
\text { Kim et al., 2010; } \\
\text { Stegall et al., 2012) }\end{array}$ \\
\hline 5. & HAL & $\begin{array}{l}\text { Hip: F-E } \\
\text { Knee: F-E } \\
\text { Ankle: F-E (U) } \\
1 \text { leg }\end{array}$ & DC Servo motor & Harmonic drives & sEMG signals & $\begin{array}{l}\text { Proportional } \\
\text { myoelectric control }\end{array}$ & $\begin{array}{l}\text { Kawamoto and Sankai } \\
\text { (2004; Suzuki } \text { et al., } \\
\text { 2005; Kawamoto et al., } \\
\text { 2009) }\end{array}$ \\
\hline 6. & REWALK & $\begin{array}{l}\text { Hip: F-E(A) } \\
\text { Knee: F-E(A) } \\
\text { Foot: F-E(U) } \\
2 \text { legs }\end{array}$ & DC motor & - & $\begin{array}{l}\text { Motion sensor, } \\
\text { tilt sensor }\end{array}$ & $\begin{array}{l}\text { Proportional } \\
\text { myoelectric } \\
\text { control }\end{array}$ & $\begin{array}{l}\text { Zeilig et al. (2012; } \\
\text { Esquenazi et al., 2012) }\end{array}$ \\
\hline 7. & ELEGS & $\begin{array}{l}\text { Hip: A-A (U) } \\
\text { F-E (A) } \\
\text { Knee: F-E (A) } \\
\text { Ankle: F-E (U) }\end{array}$ & $\begin{array}{l}\text { Hydraulic } \\
\text { actuator }\end{array}$ & - & $\begin{array}{l}\text { Switching } \\
\text { system }\end{array}$ & $\begin{array}{l}\text { Finite state } \\
\text { machine }\end{array}$ & Strickland (2019) \\
\hline 8. & $\begin{array}{l}\text { Vanderbilt } \\
\text { exoskeleton }\end{array}$ & $\begin{array}{l}\text { Hip: F-E (A) } \\
\text { Knee: F-E (A) } \\
2 \text { legs }\end{array}$ & Electric motor & - & $\begin{array}{l}\text { Using user vocal } \\
\text { commands, Center } \\
\text { of Pressure triggered }\end{array}$ & $\begin{array}{l}\text { Proportional } \\
\text { myoelectric } \\
\text { control }\end{array}$ & Farris et al. (2013) \\
\hline 9. & ATLAS & $\begin{array}{l}\text { Hip: F-E (A) } \\
\text { Knee: F-E (A) } \\
\text { Ankle: F-E(U) }\end{array}$ & $\begin{array}{l}\text { Brushless DC } \\
\text { motor }\end{array}$ & Mechanical linkage & $\begin{array}{l}\text { Switching via the } \\
\text { user interface }\end{array}$ & $\begin{array}{l}\text { Finite state } \\
\text { machine/PD } \\
\text { control }\end{array}$ & $\begin{array}{l}\text { Sanz-Merodio et al. } \\
\text { (2012) }\end{array}$ \\
\hline 10. & MINA & $\begin{array}{l}\text { Hip: F-E (A) } \\
\text { Knee: F-E (A) } \\
\text { Ankle: F-E(U) } \\
2 \text { legs }\end{array}$ & $\begin{array}{l}\text { Brushless DC } \\
\text { motor }\end{array}$ & Mechanical linkage & $\begin{array}{l}\text { Switching via the } \\
\text { user interface }\end{array}$ & PD control & Neuhaus et al. (2011) \\
\hline 11. & Mind walker & $\begin{array}{l}\text { Hip: A-A (A) } \\
\text { F-E(A) } \\
\text { Knee: F-E(A) } \\
\text { Ankle: F-E (U) } \\
2 \text { legs }\end{array}$ & $\begin{array}{l}\text { SEA Compliant } \\
\text { actuator, Springs }\end{array}$ & Mechanical linkage & $\begin{array}{l}\text { Switching via the } \\
\text { user interface }\end{array}$ & $\begin{array}{l}\text { Model predictive } \\
\text { control-based gait } \\
\text { pattern generation }\end{array}$ & Wang et al. (2013) \\
\hline 12. & $\begin{array}{l}\text { AssistON- } \\
\text { Gait }\end{array}$ & Pelvis-Hip: $6 \mathrm{DOF}$ & $\begin{array}{l}\text { SEA Compliant } \\
\text { actuator }\end{array}$ & Cable pulley system & $\begin{array}{l}\text { Switching via the } \\
\text { user interface }\end{array}$ & $\begin{array}{l}\text { Manual start/stop } \\
\text { and speed varying } \\
\text { operation }\end{array}$ & Munawar et al. (2015) \\
\hline 13. & $\begin{array}{l}\text { Ortholeg and } \\
\text { Ortholeg } 2.0\end{array}$ & $\begin{array}{l}\text { Hip: F-E (A) } \\
\text { A-A (U) } \\
\text { Knee: F-E (A) } \\
\text { Ankle: F-E(U) }\end{array}$ & DC motor & Mechanical linkage & $\begin{array}{l}\text { Electrooculography } \\
\text { and switches }\end{array}$ & Brain wave control & $\begin{array}{l}\text { Araujo et al. (2015; } \\
\text { Gloger et al., 2015) }\end{array}$ \\
\hline 14. & $\begin{array}{l}\text { Walking } \\
\text { Assistance } \\
\text { lower limb } \\
\text { exoskeleton }\end{array}$ & $\begin{array}{l}\text { Hip: F-E (A) } \\
\text { A-A (U) } \\
\text { Knee: F-E (A) } \\
\text { Ankle: U }\end{array}$ & $\begin{array}{l}\text { DC Brushless } \\
\text { motor }\end{array}$ & Harmonic drives & $\begin{array}{l}\text { Inclinometer and } \\
\text { force sensor }\end{array}$ & $\begin{array}{l}\text { Center of Pressure } \\
\text { Control }\end{array}$ & Kim et al., (2013) \\
\hline 15. & $\begin{array}{l}\text { IHMC } \\
\text { mobility assist } \\
\text { exoskeleton }\end{array}$ & $\begin{array}{l}\text { Hip: F-E (A), } \\
\text { A-A (A), R-R (U) } \\
\text { Knee: F-E (A) } \\
\text { Ankle: F-E (U) }\end{array}$ & $\begin{array}{l}\text { Rotary series } \\
\text { elastic actuator }\end{array}$ & Harmonic drives & $\begin{array}{l}\text { Optical encoder } \\
\text { works as a passive } \\
\text { force sensor }\end{array}$ & $\begin{array}{l}\text { Position, force/ } \\
\text { torque control }\end{array}$ & Kwa et al. (2009) \\
\hline 16. & $\begin{array}{l}\text { Lower-limb } \\
\text { power assist } \\
\text { exoskeleton }\end{array}$ & $\begin{array}{l}\text { Hip: F-E } \\
\text { Knee: F-E } \\
\text { Ankle: U }\end{array}$ & $\begin{array}{l}\text { BLDC motor } \\
\text { based series } \\
\text { elastic actuator }\end{array}$ & $\begin{array}{l}\text { Two stages reduction } \\
\text { gear mechanism }\end{array}$ & Torque sensor & $\begin{array}{l}\text { PI velocity control } \\
\text { loop nested in a } \\
\text { torque control loop }\end{array}$ & $\begin{array}{l}\text { Tagliamonte } \text { et al. } \\
\text { (2013) }\end{array}$ \\
\hline 17. & $\begin{array}{l}\text { Wearable Power- } \\
\text { Assist Locomotor } \\
\text { (WPAL) }\end{array}$ & $\begin{array}{l}\text { Hip: F-E (A) } \\
\text { Knee: F-E(A) } \\
\text { Ankle: F-E(U) }\end{array}$ & DC servo motor & Harmonic drives & $\begin{array}{l}\text { Encoder and force } \\
\text { sensor }\end{array}$ & $\begin{array}{l}\text { Swing phase step } \\
\text { trajectory control }\end{array}$ & Jianfeng et al. (2013) \\
\hline 18. & ABLE & $\begin{array}{l}\text { Hip: F-E } \\
\text { Knee: F-E } \\
\text { Ankle: F-E }\end{array}$ & DC motor & $\begin{array}{l}\text { Ball screw } \\
\text { mechanism, Worm } \\
\text { gear, }\end{array}$ & $\begin{array}{l}\text { Inclinometer, } \\
\text { mechanical and touch } \\
\text { switch, measurement } \\
\text { wheel, load cell, } \\
\text { potentiometer }\end{array}$ & PD control & Mori et al. (2006) \\
\hline
\end{tabular}


Sk. Khairul Hasan and Anoop Kumar Dhingra / Journal of Mechatronics and Robotics 2020, Volume 4: 211.235 10.3844/jmrsp.2020.211.235

\begin{tabular}{|c|c|c|c|c|c|c|}
\hline 19. Body Extender & $12 \mathrm{DoF}$ for both legs & PM DC motor & $\begin{array}{l}\text { Ball screw } \\
\text { mechanism, lever } \\
\text { mechanism, tendon } \\
\text { pulley mechanism }\end{array}$ & $\begin{array}{l}\text { Force sensor, } \\
\text { Accelerometer }\end{array}$ & - & $\begin{array}{l}\text { Marcheschi et al. } \\
\text { (2011) }\end{array}$ \\
\hline 20. Nurse robot suit & $\begin{array}{l}\text { Supports shoulder, } \\
\text { waist, legs }\end{array}$ & $\begin{array}{l}\text { Micro air pump } \\
\text { for rotating } \\
\text {.pneumatic } \\
\text { actuators }\end{array}$ & $\begin{array}{l}\text { Pneumatic rotatory } \\
\text { actuator }\end{array}$ & $\begin{array}{l}\text { Pressure sensor, } \\
\text { Muscle hardness } \\
\text { sensor }\end{array}$ & PID control & $\begin{array}{l}\text { Yoshimitsu and } \\
\text { Yamamoto (2004; } \\
\text { Yamamoto et al., } \\
\text { 2004) }\end{array}$ \\
\hline 21. XoR & $\begin{array}{l}\text { Hip: F-E(A) A-A(U) } \\
\text { RR(U) Knee: F-E(A) } \\
\text { Ankle: F-E(A)PS(U) }\end{array}$ & $\begin{array}{l}\text { Hybrid pneumatic } \\
\text { and electric }\end{array}$ & - & EMG signal, & - & $\begin{array}{l}\text { Hyon et al. (2011; } \\
\text { Morimoto } \text { et al., 2012) }\end{array}$ \\
\hline 22. Soft Exosuit & $\begin{array}{l}\text { Flexible strap with } \\
\text { infinite DoF }\end{array}$ & $\begin{array}{l}\text { Direct drive } \\
\text { actuator }\end{array}$ & Bowden cable & $\begin{array}{l}\text { Customized silicon- } \\
\text { based feedback } \\
\text { sensor, Load cell, } \\
\text { mechanical switch }\end{array}$ & $\begin{array}{l}\text { Trajectory based } \\
\text { position control }\end{array}$ & Asbeck et al. (2013) \\
\hline $\begin{array}{l}\text { 23. } \\
\text { Barkeley } \\
\text { Exoskeleton } \\
\text { System }\end{array}$ & $\begin{array}{l}\text { Hip: F-E (A), } \\
\text { A-A (A), } \\
\text { R (U) } \\
\text { Knee: F-E (A) } \\
\text { Ankle:A-A(U), } \\
\text { F-E(A) R, } \\
\text { Toe: F-E }\end{array}$ & $\begin{array}{l}\text { Hydraulic piston } \\
\text { cylinder }\end{array}$ & Mechanical linkage & $\begin{array}{l}\text { Force sensor, } \\
\text { encoder }\end{array}$ & $\begin{array}{l}\text { Force position } \\
\text { hybrid controller }\end{array}$ & $\begin{array}{l}\text { Zoss et al. (2006; } \\
\text { Kazerooni et al., 2006) }\end{array}$ \\
\hline 24. AAFO & Ankle: F-E(A) & $\begin{array}{l}\text { BLDC motor, } \\
\text { MACCEPA }\end{array}$ & $\begin{array}{l}\text { Ball screw, } \\
\text { Mechanical lever }\end{array}$ & $\begin{array}{l}\text { Optical encoder, } \\
\text { Absolute magnetic } \\
\text { encoder }\end{array}$ & - & Moltedo et al. (2016) \\
\hline 25. CUHK-Exo & $\begin{array}{l}\text { Hip: F-E (A), R } \\
\text { Knee: F-E (A) } \\
\text { Ankle: F-E(P) }\end{array}$ & DC motor & $\begin{array}{l}\text { Planetary gearbox, } \\
\text { Bevel gearbox }\end{array}$ & $\begin{array}{l}\text { Encoder, } \\
\text { potentiometer, } \\
\text { Inertia measurement } \\
\text { unit, Force-sensitive } \\
\text { resistor, mechanical } \\
\text { switch }\end{array}$ & PD controller & $\begin{array}{l}\text { Chen et al. (2017; } \\
\text { 2019) }\end{array}$ \\
\hline
\end{tabular}
Supination

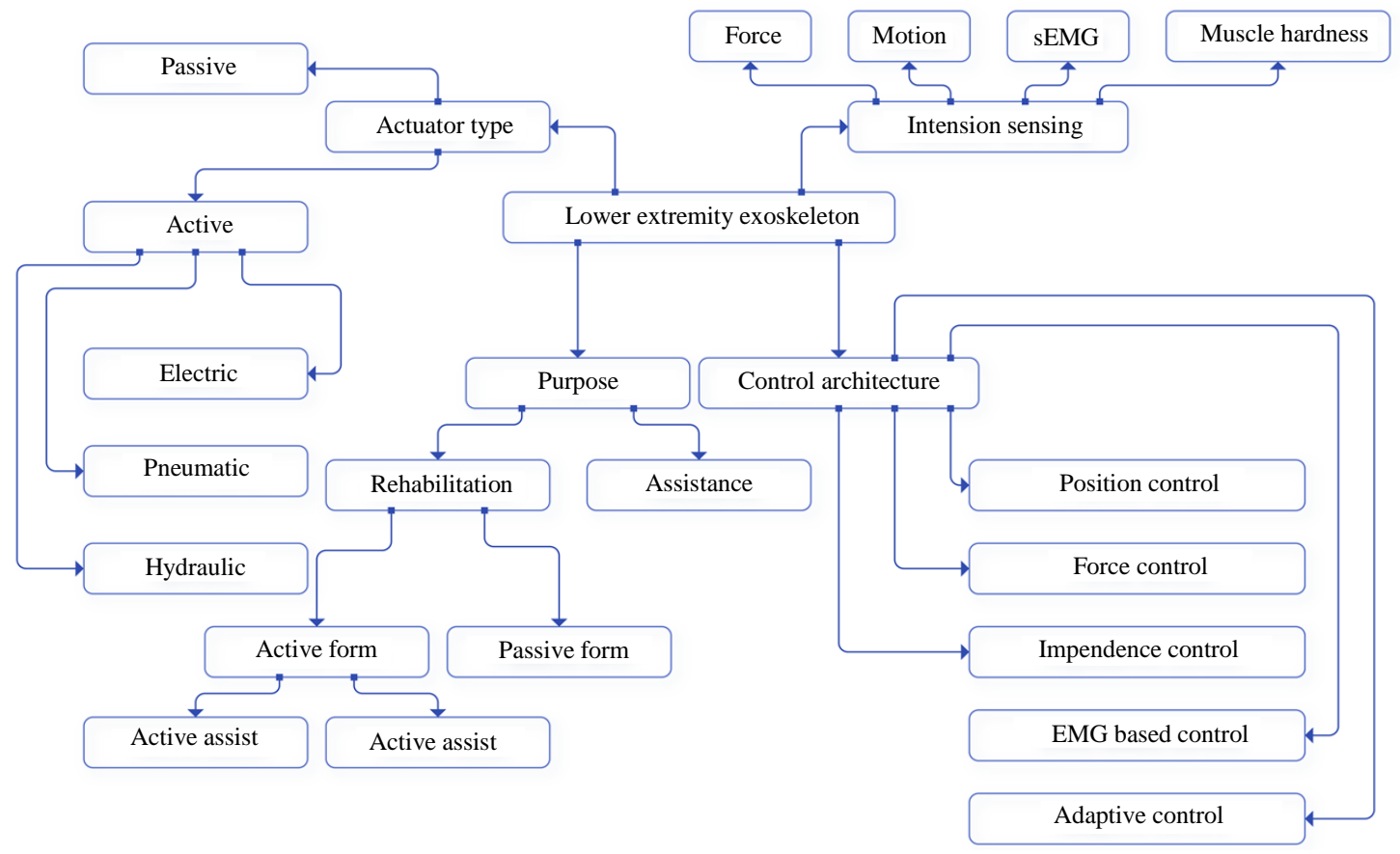

Fig. 9: Classification of lower extremity exoskeleton based on different criteria

In the next couple of subsections, different types of actuators commonly used for exoskeleton robots are discussed along with their selection criteria and control strategies.

\section{Passive Actuators}

Passive actuators don't require any power to operate. Based on the application requirement(s), a passive actuator is used individually or in combination 
with an active actuator. Passive actuators play a vital role in the design and development of energy-efficient robots. Springs are commonly used as the standard form of passive actuators in robotics applications (McGeer, 1990). Collins et al. (2001) presented applications of passive actuators in bipedal walkin. Some existing robots which have used spring as a passive actuator are discussed in (Wang et al., 2013; Banala et al., 2007; Strickland, 2019).

\section{Active Actuators}

A majority of the actuators used in robotics applications are active actuators. Active actuators need a power supply to function. They are comparatively expensive and need a sophisticated control system to operate. The major types of active actuators include the electric actuator, the hydraulic actuator and the pneumatic actuator. Every actuator type has its advantages and disadvantages. A proper selection of actuators plays a vital role in robot design and development. Presented next is a brief description of the working principles of different types of actuators, their applications, along with representative works that employ these actuators.

\section{Electric Actuator}

The most common type of actuator used in robotics applications is the electric actuator. High peak torque, the flexibility of motion control, low operating and maintenance costs, reliability, workability in a high bandwidth system, compact shape and size have made electric actuators very popular for robotics applications. There are different types of electric actuators available (Krishnan, 2001). Based on the application requirements, a suitable electric actuator is selected. Presented next is a brief description of different types of electric actuators.

\section{Motor}

A DC motor is one of the most common types of actuators used in robotics applications. Based on the electrical configuration between the stator and rotor magnetic field coil, the DC motor can be classified as a series-wound, shunt-wound, or compound wound motor. In the case of Permanent Magnet (PM) DC motor, the stator field coil is replaced by a set of permanent magnets. Each type of motor is characterized by its torque-speed relation curve, which expresses the operating characteristics at different loading conditions. Figure 10 shows the characteristics curves of different types of DC motors. In the case of PM DC motor, since the motor speed decreases proportionally with the load, such motors are not suitable for constant speed applications. A shunt-wound DC motor is less sensitive to the load around the rated motor capacity but at loads exceeding two times the rated load, the speed falls very sharply. From the motor characteristic curve, it can be seen that the series-wound DC motor is capable of providing a high starting torque (as high as eight times of the rated torque). The speed of a series-wound DC motor is more sensitive to the load. They are good for the applications that require variable speed and higher starting torques. In compound wound motors, the field coils are connected in both series and parallel combination with the rotor coils. They exhibit characteristics between the shunt and series-wound motors.

The DC motor speed is controlled by varying motor torque as the torque is proportional to the current through the motor windings. Electronic driver circuits control the current to control the torque. A use of DC motors as the major actuator in the robots can be found in (Zeilig et al., 2012; Esquenazi et al., 2012; Kong and Jeon, 2006; Colombo et al., 2000; Bernhardt et al., 2005; Araujo et al., 2015; Gloger et al., 2015; Mori et al., 2006; Marcheschi et al., 2011; Chen et al., 2017; 2019).

\section{AC Motor}

AC motors are less expensive compared to the DC motor. AC motors can have different torque-speed characteristics curves, which makes them an excellent choice for various applications. If AC power is supplied directly from the AC supply line, then these motors are limited to a few different speeds because the motor speed has a direct relationship with the supply voltage frequency. The running speed can be varied by using an inverter. Another option is to use a mechanical gearbox to change speeds and available torque. AC motors can be subdivided as a synchronous motor and asynchronous motor. Synchronous motor speed has a relation with the AC line frequency $\left(n_{s}=\frac{120 f}{p}\right.$, where $n_{s}$ is the synchronous speed, $f$ is line frequency and $p$ is the number of motor poles), whereas asynchronous motor has a small amount of slip (typically 3 to $10 \%$ ).

\section{Brush Less DC Motor (BLDC)}

BLDC motor is also known as Electronically Commuted motor (EC) or synchronous DC motor. The BLDC motor is popular for robotics applications because of its higher efficiency, low acoustic noise and longer operating life. In a BLDC motor, the rotor consists of a set of permanent magnets and the stator is based on the electric-magnetic field. The stator magnetic field rotates continuously driven by the electronic switching circuit. The rotor always tries to synchronize with the stator's rotating magnetic field and as a result, it rotates. Like the permanent magnet DC motor, no electric medium required for carrying current to the rotor. Many of the existing lower extremity rehabilitation robots use a BLDC motor. A list of representative works include (Neuhaus et al., 2011; Sanz-Merodio et al., 2012; Kim et al., 2013; Tagliamonte et al., 2013; Moltedo et al., 2016). 


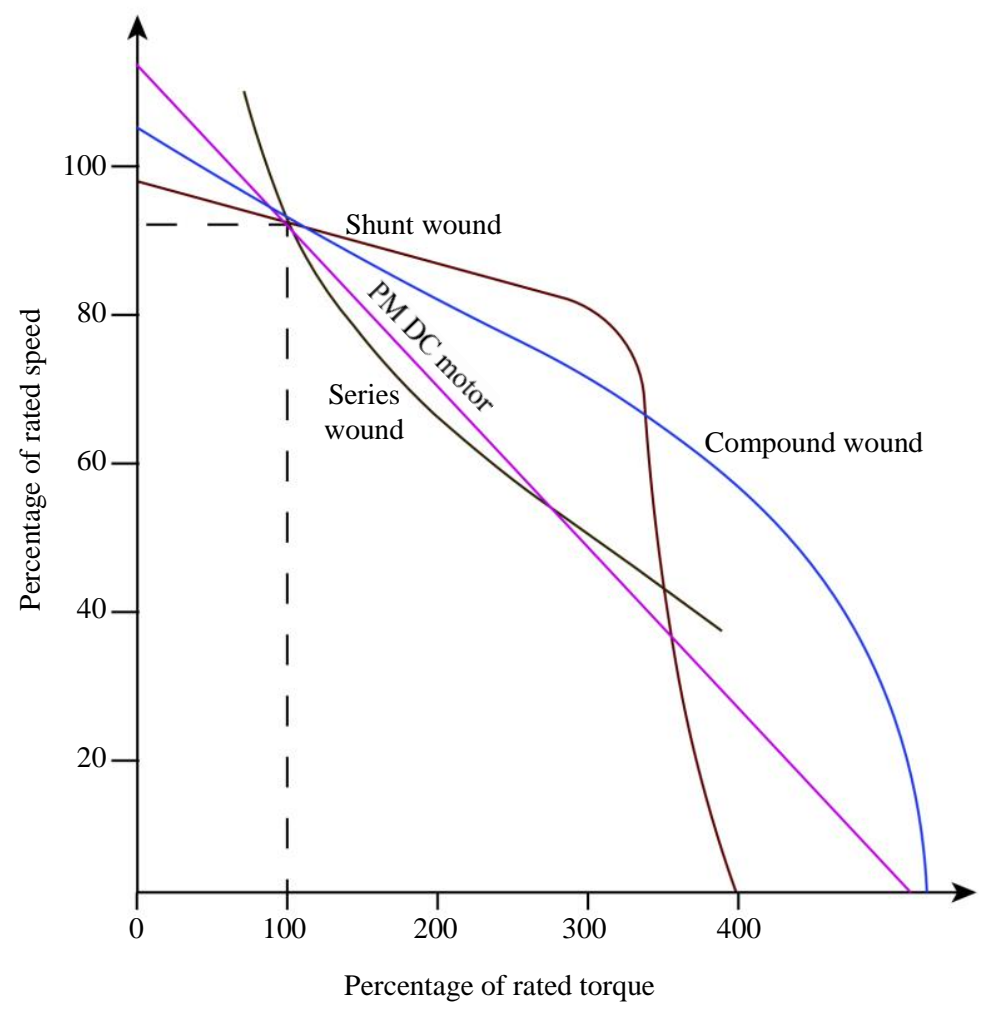

Fig. 10: DC motor characteristics curves

\section{Stepper Motor}

The working principle of the stepper motor is similar to the BLDC motor. Typically, it runs based on open-loop control architecture. As no feedback system exists in an open-loop control system, the rotor position can be out of phase at any instant. To deal with this problem, often, little extra power is added with the calculated power of the motor. The main advantage of a stepper motor is that they can sit energized for an extended period (although the temperature rises as high as $150^{\circ} \mathrm{F}$ ). The number of magnetic strips arranged around the circumference of the rotor determines the resolution of the motor (typically 200 steps/rev). With the help of a micro-stepping stepper motor driver, the resolution can be increased as high as 2000 steps/rev. The main difference between the BLDC motor and stepper motor is that the BLDC motor runs more smoothly than the stepper motor, while the stepper motor is very good at providing holding torque.

\section{Servomotor}

Servo motor refers to a complete actuation system that includes the motor (based on the application requirements $\mathrm{AC} / \mathrm{DC}$ motor can be used), driver, motor position/velocity sensor (encoder/tachometer) that runs based on some close loop control algorithms. AC motor based servo systems are more popular because they can be run at a wide variety of speeds by varying the supply voltage frequency. AC synchronous motor speed becomes fixed at a specific value based on the AC line frequency, which is called the synchronous speed of the motor. A servo motor is capable of providing a programmed function of position, velocity, acceleration and torque. A servo system is popular because of its fast response, high efficiency and high torque to inertia ratio. The following references used servo motors as the major actuator for their robots (Kawamoto and Sankai, 2004; Suzuki et al., 2005; Kawamoto et al., 2009; Jianfeng et al., 2013).

\section{Series Elastic Actuator}

The Series Elastic Actuator (SEA) is a relatively new concept introduced by (Williamson and Robinson, 1995). In the conventional robotic system, the actuator is rigidly attached to the load. A force or a torque sensor is placed in between them to measure the flow of force or torque to feedback to the control system. In some cases, the motor current is measured to estimate the motor torque. But in the case of a series elastic actuator, instead of using a force, torque, or current sensor, the spring's displacement is used to measure force/torque passively. The spring allows the load to move freely. Figure 11 shows a common configuration of a series elastic actuator. A pair of springs is attached in antagonist configuration. With the help of two encoders, the change of spring length is measured. 


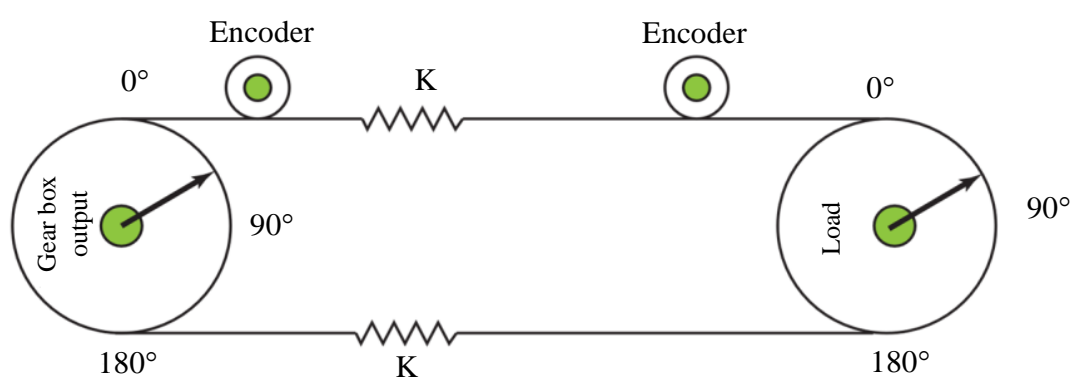

Fig. 11: Series elastic actuator

The Hooke's law defines the relationship between the force $(F)$ and displacement of the spring $(X)$ as:

$$
F=K X
$$

In the Equation (22), $F$ is the force, $K$ is the spring stiffness (constant for a specific spring) and $X$ is the displacement. In the above equation, the force can be measured with the help of displacement. A similar principle is applicable for torsional spring. Nowadays, SEA is widely used in rehabilitation robotics. The following references use series elastic actuators (Kwa et al., 2009; Veneman et al., 2007a; 2007b Wang et al., 2013; Veneman et al., 2005; Munawar et al., 2015; Tagliamonte et al., 2013;). Krishnan has discussed the modeling, analysis and control techniques of all the above mentioned electric actuators in-depth (Krishnan, 2001).

\section{Hydraulic Actuation System}

The hydraulic actuation system is more suitable for high power-weight ratio applications. Both linear and rotary hydraulic actuators are available. The efficiency of the hydraulic system is less than that of an electric system. The hydraulic system does not require reduction gears. It can work for a wide range of bandwidths. The hydraulic system requires a pump, reservoir, motor and hoses. Operating temperature affects the system performance (since fluid viscosity varies with temperature). The following references discuss some robots actuated using hydraulic actuation system (Strickland, 2019; Zoss et al., 2006; Kazerooni et al., 2006; Lee et al., 2020; Scheidl et al., 2018).

\section{Pneumatic Actuation System}

The pneumatic system runs using compressed air. Pneumatic systems are comparatively inexpensive and have been used in many exoskeleton robots. Position control applications are challenging in the pneumatic system than other types of actuation mechanisms. The main drawbacks of the pneumatic systems are that they are noisy and very difficult to control. The pneumatic system deforms under constant loading conditions. It provides the lowest power-weight ratio. The McKibben type of artificial muscle is one of the best examples of a pneumatic actuator.

\section{McKibben Artificial Muscle}

The McKibben artificial muscle was introduced in the 1950s (Gavrilović and Marić, 1969). It is one of the best examples of a pneumatic actuators for an exoskeleton robot (Kobayashi and Hiramatsu, 2004; Noritsugu et al., 2007). Currently, most of the Pneumatic Artificial Muscles (PAM) is based on McKibben artificial muscles. It consists of an internal bladder plaited by a flexible, but non-extensible mesh. The ends of the bladder are firmly attached to both ends of the mesh. When the inner bladder pressurized, the bladder expands to maximize the volume. Due to the action of non-extensile mesh, the whole system expands radially and shortens axially. McKibben artificial muscle possesses the following mechanical properties: Spring with variable stiffness, nonlinear passive elasticity, flexible and very lightweight (Hannaford and Winters, 1990).

Chou and Hannaford (1996) developed a linear model of the McKibben pneumatic artificial muscles. Wickramatunge and Leephakpreeda (2010) studied different properties of pneumatic artificial muscles, including the relation between pressure, force, length, stiffness, elastic force. The relationship between the activation level and length, velocity, tension varies with the physical construction of the artificial muscle and needs to be modeled for the individual prototype. McKibben artificial muscle is used in pairs and antagonistic configuration to increase the joint stiffness. Teng et al. (2016) characterized the activation, displacement and velocity in the case of the opposing pair configuration. Zhang et al. (2008) presented the modeling and control of pneumatic muscle actuator for the elbow exoskeleton. They developed a fuzzy logic controller for controlling a pair of antagonistic pneumatic artificial muscles for the elbow exoskeleton. 


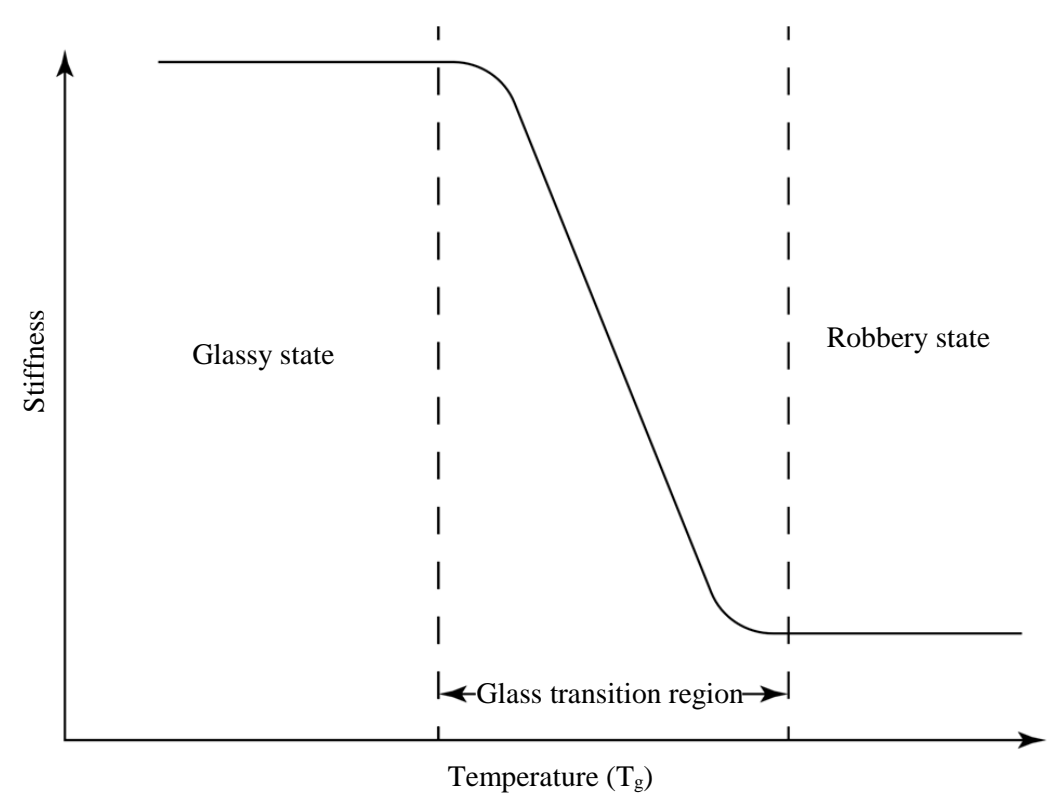

Fig. 12: Temperature Stiffness relationship of the shape memory polymer

\section{McKibben Artificial Muscle Using Shape Memory Polymer}

The main drawback of McKibben Artificial Muscle is that it needs continuous control for position tracking, which makes it challenging for real-life applications. Using a shape memory polymer can solve this problem (Sokolowski et al., 1999; Tobushi et al., 2001; 2003; Ishizawa et al., 2003; Behl and Lendlein, 2007; Huang et al., 2005; Baer et al., 2007; Lendlein and Langer, 2002; Lan et al., 2009; Xie, 2010). Shape memory polymer consists of two phases, the hard phase and the soft phase. At any temperature lower than the glass transition temperature $\left(T_{g}\right)$ temperature, it has higher stiffness and is considered a hard phase or "glassy" phase. At temperatures above the glass transition temperature, it exhibits a lower stiffness. This is called the soft phase or "rubbery" phase. Figure 12 shows the temperature stiffness relationship of the shape memory polymer.

Takashima et al. (2010) developed McKibben artificial muscle using shape-memory polymer and showed its effectiveness in robotic applications.

\section{Mechanical Power Transmission System}

A majority of the robots are actuated by electric actuators. Most of the electric motors run at high speed and deliver a small amount of torque. But for the robotics application, low speeds and high torques are required. To fulfill these requirements, mechanical power transmission is used. Mechanical power transmission can be done in several ways such as using gears of different types/sizes, belt drives, chain drives, sun planet gearbox, strain wave gearing, synchronous belt and timing pulley, etc.

Each type of transmission mechanism has its pros and cons. The selection of suitable mechanical power transmission depends on many factors such as the robot end-effector accuracy and precision requirements, overall cost, shape and size factors, mechanical power loss, cost of the actuator, environment, total power consumption, direction of power flow, mechanical noise and vibrations, etc. A brief description of different types of mechanical power transmission options along with their pros and cons are given below.

\section{Gear Drive}

The gear drive is the most common type of mechanical power transmission system with applications ranging from small precision settings to large applications. Gear drives can be used for controlling speed, torque and rotational direction. The most common type of gear is the spur gear. The gear teeth are parallel to the shaft on which the gear is mounted. Spur gears transmit power between two parallel axes. The main drawback of a spur gear based power transmission system is that it provides a significant amount of backlash. As robotics applications require high precision, an antibacklash mechanism is widely used to compensate for mechanical backlash.

A helical gear is very similar to spur gear. The main difference between the spur gear and helical gear's teeth is that helical gear teeth are not parallel to the power transmission axes. Helical gears also have 
reduced backlash compared to spur gears. They make less noise and induce lesser vibrations. The bevel gear is used for power transmission between two nonparallel/intersecting shafts. It affords a compact arrangement. There four types of bevel gears: Straight bevel gear, spiral bevel gear, zero bevel gear and hypoid bevel gears. The worm gear is used for power transmission between two nonparallel nonintersecting shafts. Figure 13 presents different types of gears widely used for mechanical power transmission. An application of bevel gears in the robot power transmission system can be found in (Kong and Jeon, 2006; Mori et al., 2006; Chen et al., 2017; 2019).

\section{Belt Drive}

The belt drive is used to transmit power between two shafts. There are three types of belts: Flat belt, V-belt and the toothed belt. Flat belt and V-belt are based on friction between the belt and the pulley; as a result, belt slippage can cause problems. The synchronous belt (toothed belt) eliminates the risk of slippage. Such belts are widely used for robotics applications.

\section{Sun Planet Drive}

The sun planet gear system, also known as the epicyclic gear train, is a compact way to provide a higher gear ratio (higher torque and lower speed). The epicyclic gear system has three main parts, sun, planet and the outer ring gear. Based on the internal architecture of the epicyclic gear train, it is two degrees of freedom system, i.e., the user can control the output, including torque, speed, the direction of rotation by controlling two input variables. In the case of robotics application, only one degree of freedom is used as the ring gear is kept stationary. Many times, a multistage epicyclic gear train is used to get a more compact gearing system. Some representative works on the use of epicyclic gear train for robotic applications include (Tagliamonte et al., 2013; Chen et al., 2017; 2019). Figure 14 and 15 show the internal architecture and a multistage sun planet gear system.

\section{Strain Wave Drive}

Strain wave gearing is also known as a harmonic drive. It is widely used for robotics applications and possesses many excellent qualities such as: (i) Almost zero backlash, (ii) compact design, (iii) lightweight, (iv) high gear ratio, (v) good resolution, (vi) excellent repeatability, (vii) high torque capability, (viii) coaxial input-output shaft and (ix) very high gear ratio in a single stage (typically 30:1 to 320:1).

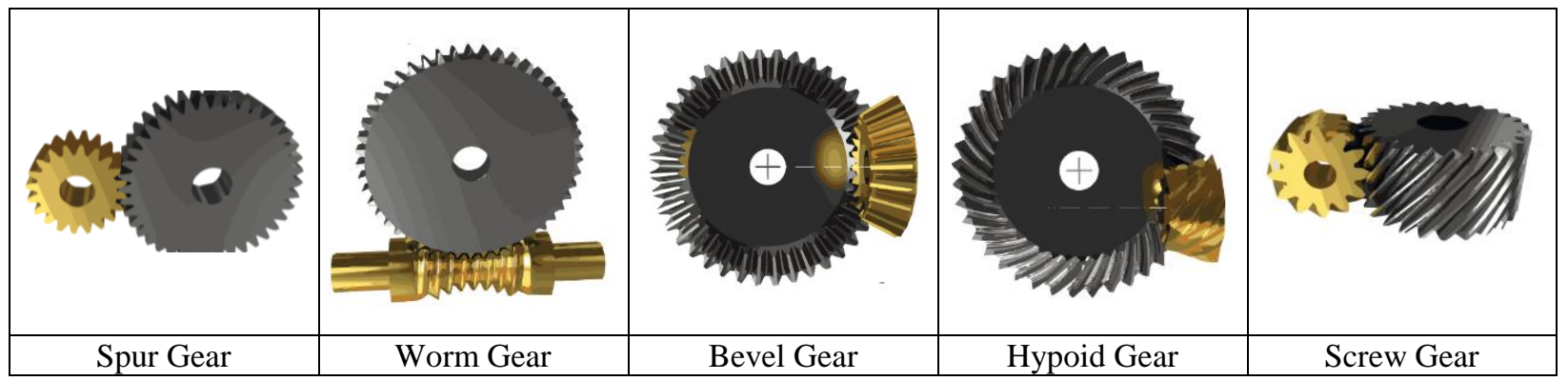

Fig. 13: Spur gear, Worm gear, Bevel gear, Hypoid gear, Screw gear
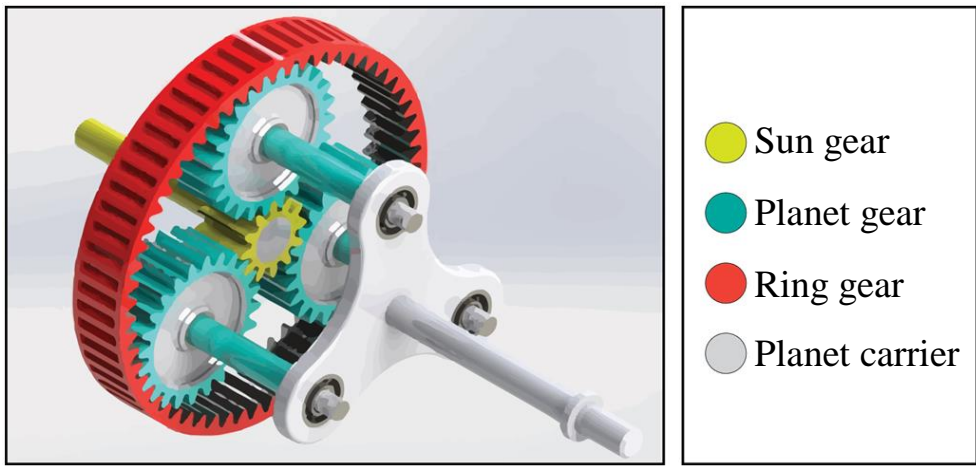

Fig. 14: Sun planet gear system 


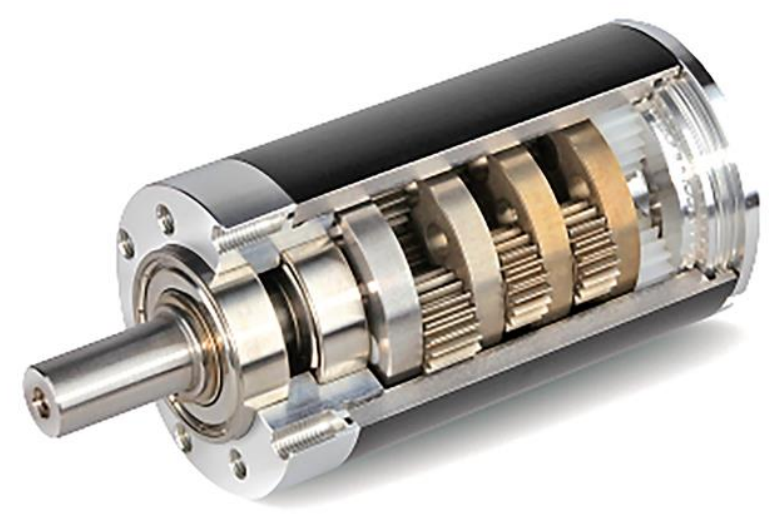

Fig. 15: Multistage sun planet gear system

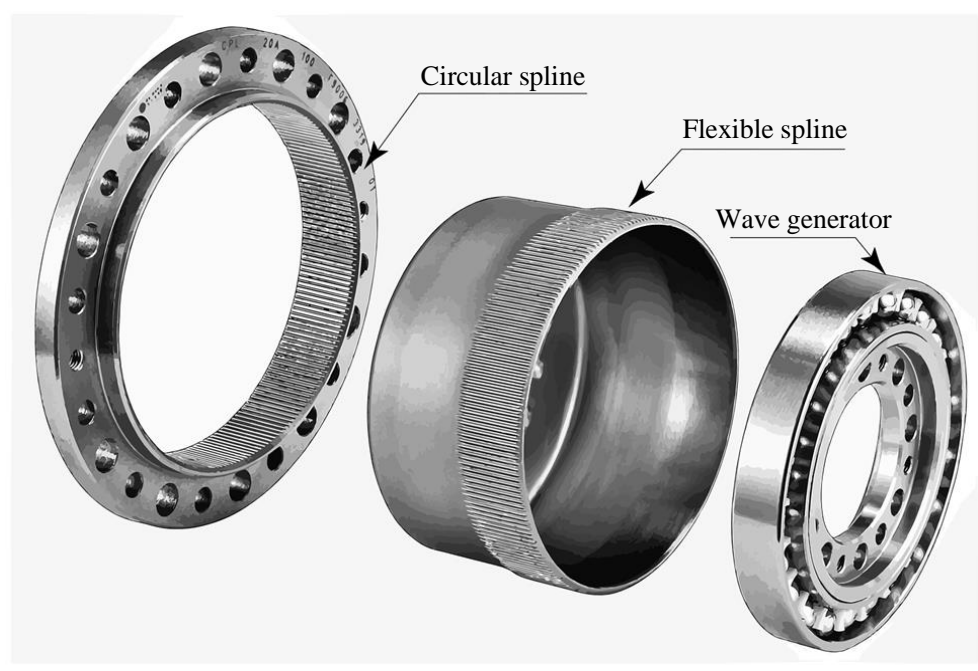

Fig. 16: Strain wave generator

The strain wave drive is built based on the elastic/flexible properties of the metal. It has three major components: A wave generator, flexible-spline and a circular spline (Fig. 16). The source is connected to the wave generator and the output is connected to the flex spline. A wave generator is an epicyclic disk covered by ball bearings. The outer cage of the ball bearings is made of flexible metal that allows changing of the shape during rotation. The wave generator is inserted into the flexible spline (a flexible shallow metallic cap with a finite number of teeth on the outer side). The flexible spline is made of flexible material and due to the action of the inside epicyclic disk, the flex spline continuously changes its shape. The major axis of the flex spline rotates with the wave generator and the flex spline meshes with the circular spline only at a few teeth. For every rotation of the wave generator, the flex spline advances a very small amount. Some references that have used strain wave generator based gear reduction system include (Kwa et al., 2009; Kawamoto et al., 2009; Kawamoto and Sankai, 2004; Suzuki et al., 2005; Kim et al., 2013; Jianfeng et al., 2013).

\section{Bowden Cable}

In the conventional power transmission system, the motor and the gearbox stay close to the joint. The main drawbacks of the conventional power transmission system are: They make the exoskeleton robot heavy and large. The robot consumes extra power for carrying the motor and the gearbox and requires a strengthening of mechanical structures. All these problems can be solved with the help of the Bowden cable-based power transmission system. In the Bowden cable-based power transmission system, the actuators are located at a distant place. Mechanical power is transmitted to the joints via cables. The main drawback of the Bowden 
tube-based transmission system is that introduces a significant amount of backlash. If the gearbox is attached to the motor at a distant location, then the system gives more backlash, whereas if the gearbox is located at the joint and the motor is at a distant location, the backlash gets divided by the gear ratio and becomes small. There are many robotic rehabilitation system where the Bowden cable-based power transmission system is used such as (Kong and Jeon, 2006; Veneman et al., 2005; Munawar et al., 2015; Marcheschi et al., 2011; Asbeck et al., 2013; Veneman et al., 2007b; Ekkelenkamp et al., 2005).

\section{Ball Screw}

The ball screw is a linear actuator that converts rotatory motion into linear motion. The basic components of a ball screw mechanism are a screw with helical grooves on its body, balls and a nut. The ball stays between the screw and the nut. The balls are routed in a continuous path. The following specifications characterize the ball screw mechanism: Lead accuracy, axial play, preload and life/load relationship. The ball screw is a popular mechanism in robotic applications as it provides high accuracy and efficiency. A use ball screw based power transmission in robots can be found in (Colombo et al., 2000; Bernhardt et al., 2005; Mori et al., 2006; Marcheschi et al., 2011; Moltedo et al., 2016).

\section{Intention Sensing System}

The user's intention sensing, measurement and proper interpretation are vital for selecting active, active assist or active resist forms of physical therapy. For the active form of robotic neurorehabilitation, the exoskeleton robot's assistance or degree of involvement depends on the user's intention. There are many ways to sense and interpret user's intentions, such as sensing force or torque, sensing different forms of motion, or by analyzing biological signals from a particular or a group of muscles, including surface electromyography (sEMG), mechanomyography (MMG), pressure pattern (Force myography), etc. In the following subsections, different types of intention sensing methods are discussed that can be used for exoskeleton assisted rehabilitation applications.

\section{Force Sensing}

The force/torque sensing method is frequently used for determining the user's motion intention. Often force/torque sensors are attached between the exoskeleton robot's mechanical structures and the lower extremity to measure the force/torque exerted by the user. In many cases, force sensors are also attached at the shoe sole or the bottom of the crutches to determine the state of walking. The torque sensor is placed between the motor and the output links to feedback the output torque to the controller or to measure torque assistance provided by the robot. Depending on the output of the force/torque sensor, the robot controller makes maneuvering decisions. In the case of series elastic actuators, force/torque is measured passively with the help of displacements. The following references used force or torque sensors for interacting with the users (Veneman et al., 2007a; 2007b; Kong and Jeon, 2006; Colombo et al., 2000; Bernhardt et al., 2005; Veneman et al., 2005; Banala et al., 2007; Agrawal et al., 2007; Kim et al., 2010; Stegall et al., 2012; Kim et al., 2013; Tagliamonte et al., 2013; Jianfeng et al., 2013; Mori et al., 2006; Marcheschi et al., 2011; Yoshimitsu and Yamamoto, 2004; Asbeck et al., 2013; Zoss et al., 2006; Kazerooni et al., 2006; Chen et al., 2017; 2019).

\section{Motion Sensing}

Another popular way to sense the user's intention is to measure the motion of a specific point on the limb. The motion can be in the form of linear or rotational displacement, velocity, or acceleration. Rotatory encoders, accelerometer, inertial measurement unit, gyroscope and inclinometer sensor can be used for sensing motion. A rotatory encoder converts angular motion (angular position and velocity) into equivalent analog voltage or digital signals. The modern accelerometers are microelectromechanical devices, tiny in size, widely used for measuring acceleration forces or inclination angles. A gyroscope measures the angular velocity. Inertial Measuring Unit (IMU) is a combination of 3 axis accelerometer, a three-axis gyroscope and a magnetometer and is capable of providing absolute orientation. IMU can be used for measuring the absolute orientation of a moving body in the space. An inclinometer also can be used for measuring the absolute angles. A use of these devices can be found in (Kwa et al., 2009; Zeilig et al., 2012; Esquenazi et al., 2012; Colombo et al., 2000; Bernhardt et al., 2005; Kim et al., 2013; Jianfeng et al., 2013; Mori et al., 2006; Marcheschi et al., 2011; Zoss et al., 2006; Kazerooni et al., 2006; Moltedo et al., 2016; Chen et al., 2017; 2019).

\section{Different Forms of the Switch}

Mechanical switches can be used as sensors. Often single pole single throw switches are used as limit switches. For the user's intention sensing, different types of switches can be used, including reed switch, pillow switch, mercury switches. Pillow switch is handy for detecting the interaction between the user and the exoskeleton robot as discussed in (Neuhaus et al., 2011; Wang et al., 2013; Strickland, 2019; Sanz-Merodio et al., 2012; Munawar et al., 2015; Araujo et al., 2015; Gloger et al., 2015; Asbeck et al., 2013). 


\section{Surface Electromyography}

Electromyography (EMG) is an effective way to evaluate and record electrical activity produced by skeletal muscle during movements. Surface ElectroMyoGraphy (SEMG) is a non-invasive form of EMG. Instead of using needle, surface electromyography uses surface electrodes for picking up muscles' electrical activities. Typically, the amplitude of the signal varies from 0 to $10 \mathrm{mV}$ (peak-to-peak). The frequency of the signal varies between 0 to $500 \mathrm{~Hz}$, with the dominant energy being in the 50 to $150 \mathrm{~Hz}$ range. SEMG signals can be used for estimating the force/torque developed by an individual or group of muscles. There are different types of SEMG instruments are available in the market. Sometimes they come with additional functionalities such as real-time acceleration measurements. Modern SEMG systems use Bluetooth wireless communications, which provide more accessibility to users. SEMG applications for intention sensing is discussed in (Kawamoto et al., 2009; Kawamoto and Sankai, 2004; Suzuki et al., 2005; Wang et al., 2013; Hyon et al., 2011; Morimoto et al., 2012).

\section{Pressure Pattern (Force Myography)}

In force myography, a cuff with arrays of pressure sensors surrounding thigh, shank, or foot is used for determining different muscle activation levels. The user's movement intention can be classified based on the pattern of the force myography as explained in (Yoshimitsu and Yamamoto, 2004; Yamamoto et al., 2004).

\section{Digital Camera and Depth Sensor}

By using modern digital image processing and machine vision technologies, the individual joint angles can be measured with great precision. Microsoft Kinect combines both the digital camera and image depth sensors and includes an Application Program Interface (API) to get the readily available human upper and lower extremity joints angle (Lun and Zhao, 2015). Kinect was developed for gaming purposes, but it can be used for rehabilitation purposes. The primary application of Microsoft Kinect in rehabilitation robotics is to determine the user's intentions and to measure joint angles at any instant. Even without using Microsoft Kinect, by combining data from two sensors and by using custom algorithms, the same objective can be accomplished.

\section{Discussion}

A comprehensive review of the state-of-the-art for HLE exoskeleton robots is presented that includes detailed discussions on lower extremity anatomy, possible causes of HLE disability, rehabilitation protocols, and basic safety and ergonomic design requirements that need to be considered during design/selection of an exoskeleton robot. Both electrical and mechanical sensing and actuation technologies are discussed in depth to familiarize the reader with current technologies. A lack of commercial names and/or model information of previously used sensors and actuators should not be considered as a limitation of this paper. Instead of focusing on a specific brand, the sensor family's working principles are discussed. Attempting to explain all the previously used sensors and actuators requires a considerable amount of information which presents challenges in keeping this article of reasonable length. A comprehensive coverage of all relevant anatomical, actuation and sensing aspects of lower extremity exoskeleton robots will help a designer come up with the best possible solution for a specific application.

\section{Conclusion}

The goal of this paper was to extract and analyze information from existing lower extremity exoskeleton robots, identify the gaps and utilize them for further improvement(s) in the design of exoskeleton rehabilitation robots.

To achieve this goal, 25 existing human lower extremity exoskeleton robots were examined carefully based on published articles and relevant review papers. It was noticed information pertaining to human lower extremity anatomy was missing from exoskeleton robot design and development. The gap has been filled herein by explaining human lower extremity bones, joints, nervous system, muscles, anthropomorphic DoF, RoM and anthropometric parameters. Knowledge of human lower extremity anatomy is vital to understanding the causes of human lower extremity disability. For design, development and performance evaluation of human lower extremity exoskeleton robot, anatomical features play a crucial role.

It was also noticed that in the existing literature, there is insufficient explanation of the causes of human lower extremity disabilities. An explanation of the probable causes of human lower extremity disability is provided herein along with an explanation of how they are related to the nervous system and the muscular system.

Safety and ergonomic design are two critical aspects that need to be addressed during the design and development of human lower extremity exoskeleton robots. Safety is the first requirement for any device that deals with humans. As the lower extremity exoskeleton robot firmly attaches to the human lower extremity, the designer needs to consider safety issues seriously. Different ways to improve safety aspects from multiple dimensions were explained. Ergonomic design features help improve the user's comfort thereby helping users to exercise for a prolonged period. Techniques for incorporating ergonomic features in the exoskeleton robot were discussed. 
Different phases of neurorehabilitation and the associated physical exercises, including passive, active, active assist and active resist forms of physical therapies, were also explained.

After reviewing the existing literature, it was also noticed that no review article has addressed in depth the sensing and actuation system used for human lower extremity exoskeleton robots. The actuators act like muscles of the robot whereas the sensors help to interact with user and control of the robot. A detailed description of different types of sensors and actuators used in existing exoskeleton robots, their working principle, along with representative works, is presented.

It is hoped that a comprehensive treatment of all aspects that need to be considered while designing a lower extremity exoskeleton robot will help designers develop a good understanding of human anatomy which in turn, will facilitate the design of safe and ergonomic robots. Knowledge of disability causes will help in the selection of the best form of exercise for the patient. Comprehensive knowledge about all the sensors and actuators that are used for existing lower extremity exoskeleton robots will help the designer choose the best sensor or actuator for a specific application.

\section{Acknowledgment}

Sk. Khairul Hasan was supported by an assistantship from the Mechanical Engineering Department, University of Wisconsin-Milwaukee. This support is gratefully acknowledged.

\section{Author's Contributions}

Sk. Khairul Hasan: Literature search, paper organization and writing.

Anoop Dhingra: Paper organization, proof-reading and editing the manuscript.

\section{Ethics}

This article is original and contains unpublished material. Authors declare that are no ethical issues and no conflict of interest may arise after the publication of this manuscript.

\section{References}

Agrawal, S. K., Banala, S. K., Fattah, A., Sangwan, V., Krishnamoorthy, V., Scholz, J. P., \& Hsu, W. L. (2007). Assessment of motion of a swing leg and gait rehabilitation with a gravity balancing exoskeleton. IEEE Transactions on Neural Systems and Rehabilitation Engineering, 15(3), 410-420.

American Academy of Orthopaedic Surgeons. (1965). Joint motion: method of measuring and recording. Churchill Livingstone.
Araujo, M. V., Alsina, P. J., Roza, V. C. C., \& Melo, N. B. (2015). Powered orthosis ortholeg: Design and development. IEEE Latin America Transactions, 13(1), 90-95.

Asbeck, A. T., Dyer, R. J., Larusson, A. F., \& Walsh, C. J. (2013, June). Biologically-inspired soft exosuit. In 2013 IEEE 13th International Conference on Rehabilitation Robotics (ICORR) (pp. 1-8). IEEE.

Baer, G., Wilson, T. S., Matthews, D. L., \& Maitland, D. J. (2007). Shape-memory behavior of thermally stimulated polyurethane for medical applications. Journal of applied polymer science, 103(6), 3882-3892.

Banala, S. K., Agrawal, S. K., \& Scholz, J. P. (2007, June). Active Leg Exoskeleton (ALEX) for gait rehabilitation of motor-impaired patients. In 2007 IEEE 10th international conference on rehabilitation robotics (pp. 401-407). IEEE.

Behl, M., \& Lendlein, A. (2007). Shape-memory polymers. Materials Today 10 (4):20-28.

Bernhardt, M., Frey, M., Colombo, G., \& Riener, R. (2005, June). Hybrid force-position control yields cooperative behaviour of the rehabilitation robot LOKOMAT. In 9th International Conference on Rehabilitation Robotics, 2005. ICORR 2005. (pp. 536-539). IEEE.

Brodie, M. J., Schachter, S. C., \& Kwan, P. (2012). Fast facts: epilepsy. Karger Medical and Scientific Publishers.

Bushby, K., \& Marini-Bettolo, C. (2020). Muscular dystrophy.

Cenciarini, M., \& Dollar, A. M. (2011, June). Biomechanical considerations in the design of lower limb exoskeletons. In 2011 IEEE International conference on rehabilitation robotics (pp. 1-6). IEEE.

Chen, B., Ma, H., Qin, L. Y., Gao, F., Chan, K. M., Law, S. W., ... \& Liao, W. H. (2016). Recent developments and challenges of lower extremity exoskeletons. Journal of Orthopaedic Translation, 5, 26-37.

Chen, B., Zhong, C. H., Zhao, X., Ma, H., Guan, X., Li, X., .. \& Liao, W. H. (2017). A wearable exoskeleton suit for motion assistance to paralysed patients. Journal of orthopaedic translation, 11, 7-18.

Chen, B., Zhong, C. H., Zhao, X., Ma, H., Qin, L., \& Liao, W. H. (2019). Reference joint trajectories generation of CUHK-EXO exoskeleton for system balance in walking assistance. IEEE Access, 7, 33809-33821.

Chen, G., Chan, C. K., Guo, Z., \& Yu, H. (2013). A review of lower extremity assistive robotic exoskeletons in rehabilitation therapy. Critical Reviews $^{\mathrm{TM}}$ in Biomedical Engineering, 41(4-5).

Chou, C. P., \& Hannaford, B. (1996). Measurement and modeling of McKibben pneumatic artificial muscles. IEEE Transactions on robotics and automation, 12(1), 90-102. 
Collins, S. H., Wisse, M., \& Ruina, A. (2001). A threedimensional passive-dynamic walking robot with two legs and knees. The International Journal of Robotics Research, 20(7), 607-615.

Colombo, G., Joerg, M., Schreier, R., \& Dietz, V. (2000). Treadmill training of paraplegic patients using a robotic orthosis. Journal of rehabilitation research and development, 37(6), 693-700.

Colombo, G., Wirz, M., \& Dietz, V. (2001). Driven gait orthosis for improvement of locomotor training in paraplegic patients. Spinal cord, 39(5), 252-255.

Contini, R. (1972). Body segment parameters, Part II. Artificial limbs, 16(1), 1-19.

Ekkelenkamp, R., Veneman, J., \& van der Kooij, H. (2005, June). LOPES: Selective control of gait functions during the gait rehabilitation of CVA patients. In 9th International Conference on Rehabilitation Robotics, 2005. ICORR 2005. (pp. 361-364). IEEE.

Esquenazi, A., Talaty, M., Packel, A., \& Saulino, M. (2012). The ReWalk powered exoskeleton to restore ambulatory function to individuals with thoraciclevel motor-complete spinal cord injury. American journal of physical medicine \& rehabilitation, 91(11), 911-921.

Farris, R. J., Quintero, H. A., Murray, S. A., Ha, K. H., Hartigan, C., \& Goldfarb, M. (2013). A preliminary assessment of legged mobility provided by a lower limb exoskeleton for persons with paraplegia. IEEE Transactions on neural systems and rehabilitation engineering, 22(3), 482-490.

Florimond, V. (2008). Basics of Surface Electromyography Applied to Psychophysiology. Thought Technology Ltd, Doc Number MAR900; Montreal, Canada.

Gavrilović, M. M., \& Marić, M. R. (1969). Positional servo-mechanism activated by artificial muscles. Medical and Biological Engineering, 7(1), 77-82.

Gibson. (1990). Patterns of care for stroke survivors. Stroke. 21(9), II38-II39.

Gloger, M., Alsina, P. J., \& Melo, N. B. (2015, November). Ortholeg 2.0-a new design for a lower limb active orthosis. In 2015 International symposium on micro-nanomechatronics and human science (MHS) (pp. 1-7). IEEE.

Hannaford, B., \& Winters, J. (1990). Actuator properties and movement control: biological and technological models. In Multiple muscle systems (pp. 101-120). Springer, New York, NY.

Harstad, E., \& Albers-Prock, L. (2011). Caring for your baby and young child: Birth to age 5 .

Hasan, S. K., \& Dhingra, A. K. (2020). 8 Degrees of freedom human lower extremity kinematic and dynamic model development and control for exoskeleton robot based physical therapy. International Journal of Dynamics and Control, 1-20.
Huang, W. M., Yang, B., An, L., Li, C., \& Chan, Y. S. (2005). Water-driven programmable polyurethane shape memory polymer: demonstration and mechanism. Applied Physics Letters, 86(11), 114105.

Hyon, S. H., Morimoto, J., Matsubara, T., Noda, T., \& Kawato, M. (2011, September). XoR: Hybrid drive exoskeleton robot that can balance. In 2011 IEEE/RSJ International conference on intelligent robots and systems (pp. 3975-3981). IEEE.

Ishizawa, J., Imagawa, K., Minami, S., Hayashi, S., \& Miwa, N. (2003). Research on application of shape memory polymers to space inflatable systems. Small, 400, 500.

Jezernik, S., Colombo, G., Keller, T., Frueh, H., \& Morari, M. (2003). Robotic orthosis lokomat: A rehabilitation and research tool. Neuromodulation: Technology at the neural interface, 6(2), 108-115.

Jianfeng, S., Runze, Y., \& Linhong, J. (2013). Lowerlimb robot-assisted therapy in rehabilitation of acute and subacute stroke patients. In World Congress on Medical Physics and Biomedical Engineering May 26-31, 2012, Beijing, China (pp. 2034-2037). Springer, Berlin, Heidelberg.

Kawamoto, H., \& Sankai, Y. (2004, September). Power assist method based on phase sequence driven by interaction between human and robot suit. In ROMAN 2004. 13th IEEE International Workshop on Robot and Human Interactive Communication (IEEE Catalog No. 04TH8759) (pp. 491-496). IEEE.

Kawamoto, H., Hayashi, T., Sakurai, T., Eguchi, K., \& Sankai, Y. (2009, September). Development of single leg version of HAL for hemiplegia. In 2009 Annual international conference of the IEEE engineering in medicine and biology society (pp. 5038-5043). IEEE.

Kawamoto, H., Taal, S., Niniss, H., Hayashi, T., Kamibayashi, K., Eguchi, K., \& Sankai, Y. (2010, August). Voluntary motion support control of Robot Suit HAL triggered by bioelectrical signal for hemiplegia. In 2010 Annual International Conference of the IEEE Engineering in Medicine and Biology (pp. 462-466). IEEE.

Kazerooni, H., Steger, R., \& Huang, L. (2006). Hybrid control of the Berkeley lower extremity exoskeleton (BLEEX). The International Journal of Robotics Research, 25(5-6), 561-573.

Kendall, F. P., McCreary, E. K., Provance, P. G., Rodgers, M. M., \& Romani, W.A. (2005). Muscles: Testing and Function, with Posture and Pain. LWW.

Kim, J. H., Han, J. W., Kim, D. Y., \& Baek, Y. S. (2013). Design of a walking assistance lower limb exoskeleton for paraplegic patients and hardware validation using CoP. International Journal of Advanced Robotic Systems, 10(2), 113. 
Kim, S. H., Banala, S. K., Brackbill, E. A., Agrawal, S. K., Krishnamoorthy, V., \& Scholz, J. P. (2010). Robotassisted modifications of gait in healthy individuals. Experimental brain research, 202(4), 809-824.

Kobayashi, H., \& Hiramatsu, K. (2004, April). Development of muscle suit for upper limb. In IEEE International Conference on Robotics and Automation, 2004. Proceedings. ICRA'04. 2004 (Vol. 3, pp. 2480-2485). IEEE.

Kong, K., \& Jeon, D. (2006). Design and control of an exoskeleton for the elderly and patients. IEEE/ASME Transactions on mechatronics, 11(4), 428-432.

Krishnan, R. (2001). Electric motor drives: modeling, analysis and control. Prentice Hall.

Kurz, T. (2015). Normal Ranges of Joint Motion. http://web.mit.edu/tkd/stretch/stretching_8.html

Kwa, H. K., Noorden, J. H., Missel, M., Craig, T., Pratt, J. E., \& Neuhaus, P. D. (2009, May). Development of the IHMC mobility assist exoskeleton. In 2009 IEEE international conference on robotics and automation (pp. 2556-2562). IEEE.

Lam, T., Pauhl, K., Krassioukov, A., \& Eng, J. J. (2011). Using robot-applied resistance to augment bodyweight-supported treadmill training in an individual with incomplete spinal cord injury. Physical therapy, 91(1), 143-151.

Lan, X., Wang, X., Lu, H., Liu, Y., \& Leng, J. (2009, March). Shape recovery performances of a deployable hinge fabricated by fiber-reinforced shape-memory polymer. In Behavior and Mechanics of Multifunctional Materials and Composites 2009 (Vol. 7289, p. 728910). International Society for Optics and Photonics.

Lee, T., Lee, D., Song, B., \& Baek, Y. S. (2020). Design and Control of a Polycentric Knee Exoskeleton Using an Electro-Hydraulic Actuator. Sensors, 20(1), 211.

Lendlein, A., \& Langer, R. (2002). Biodegradable, elastic shape-memory polymers for potential biomedical applications. Science, 296(5573), 1673-1676.

Lun, R., \& Zhao, W. (2015). A survey of applications and human motion recognition with microsoft kinect. International Journal of Pattern Recognition and Artificial Intelligence, 29(05), 1555008.

Marcheschi, S., Salsedo, F., Fontana, M., \& Bergamasco, M. (2011, May). Body Extender: Whole body exoskeleton for human power augmentation. In 2011 IEEE international conference on robotics and automation (pp. 611-616). IEEE.

McGeer, T. (1990, May). Passive walking with knees. In Proceedings., IEEE International Conference on Robotics and Automation (pp. 1640-1645). IEEE.

Meng, W., Liu, Q., Zhou, Z., Ai, Q., Sheng, B., \& Xie, S. S. (2015). Recent development of mechanisms and control strategies for robot-assisted lower limb rehabilitation. Mechatronics, 31, 132-145.
Moltedo, M., Bacek, T., Junius, K., Vanderborght, B., \& Lefeber, D. (2016, June). Mechanical design of a lightweight compliant and adaptable active ankle foot orthosis. In 2016 6th IEEE International Conference on Biomedical Robotics and Biomechatronics (BioRob) (pp. 1224-1229). IEEE.

Mori, Y., Okada, J., \& Takayama, K. (2006). Development of a standing style transfer system" ABLE" for disabled lower limbs. IEEE/ASME Transactions on Mechatronics, 11(4), 372-380.

Morimoto, J., Noda, T., \& Hyon, S. H. (2012, May). Extraction of latent kinematic relationships between human users and assistive robots. In 2012 IEEE International Conference on Robotics and Automation (pp. 3909-3915). IEEE.

Munawar, H., Yalcin, M., \& Patoglu, V. (2015, August). AssistOn-Gait: An overground gait trainer with an active pelvis-hip exoskeleton. In 2015 IEEE International conference on rehabilitation robotics (ICORR) (pp. 594-599). IEEE.

Neuhaus, P. D., Noorden, J. H., Craig, T. J., Torres, T., Kirschbaum, J., \& Pratt, J. E. (2011, June). Design and evaluation of Mina: A robotic orthosis for paraplegics. In 2011 IEEE international conference on rehabilitation robotics (pp. 1-8). IEEE.

Nikolova, G., \& Toshev, Y. (2008). Comparison of two approaches for calculation of the geometric and inertial characteristics of the human body of the Bulgarian population. Acta of bioengineering and biomechanics, 10(1), 3 .

Noritsugu, T., Sasaki, D., Kameda, M., Fukunaga, A., \& Takaiwa, M. (2007). Wearable power assist device for standing up motion using pneumatic rubber artificial muscles. Journal of Robotics and mechatronics, 19(6), 619-628.

Rupal, B. S., Singla, A., \& Virk, G. S. (2016). Lower limb exoskeletons: a brief review. In Conference on mechanical engineering and technology (COMET2016), IIT (BHU), Varanasi, India (pp. 130-140).

Russell, F., Vaidyanathan, R., \& Ellison, P. (2018, August). A kinematic model for the design of a bicondylar mechanical knee. In 2018 7th IEEE international conference on biomedical robotics and biomechatronics (Biorob) (pp. 750-755). IEEE.

Sanz-Merodio, D., Cestari, M., Arevalo, J. C., \& Garcia, E. (2012). Control motion approach of a lower limb orthosis to reduce energy consumption. International Journal of Advanced Robotic Systems, 9(6), 232.

Scheidl, R., Poltschak, F., \& Rafetseder, D. (2018). Hydraulic actuation of exoskeletons-state of the art and prospects. submitted for publication as a short review article to International Robotics \& Automation Journal, 4(3). 
Shi, D., Zhang, W., Zhang, W., \& Ding, X. (2019). A review on lower limb rehabilitation exoskeleton robots. Chinese Journal of Mechanical Engineering, 32(1), 74 .

Sokolowski, W. M., Chmielewski, A. B., Hayashi, S., \& Yamada, T. (1999, May). Cold hibernated elastic memory (CHEM) self-deployable structures. In Smart Structures and Materials 1999: Electroactive Polymer Actuators and Devices (Vol. 3669, pp. 179-185). International Society for Optics and Photonics.

Stegall, P., Winfree, K. N., \& Agrawal, S. K. (2012, May). Degrees-of-freedom of a robotic exoskeleton and human adaptation to new gait templates. In 2012 IEEE International Conference on Robotics and Automation (pp. 4986-4991). IEEE.

Strickland, E. (2019). Good-bye, Wheelchair, Hello Exoskeleton. IEEE SPECTRUM. http://spectrum. IEEE. org/biomedical/bionics/goodbye-wheelchairhello-exoskeleton.

Suzuki, K., Kawamura, Y., Hayashi, T., Sakurai, T., Hasegawa, Y., \& Sankai, Y. (2005, October). Intention-based walking support for paraplegia patient. In 2005 IEEE International Conference on Systems, Man and Cybernetics (Vol. 3, pp. 2707-2713). IEEE.

Tagliamonte, N. L., Sergi, F., Carpino, G., Accoto, D., \& Guglielmelli, E. (2013, June). Human-robot interaction tests on a novel robot for gait assistance. In 2013 IEEE 13th International Conference on Rehabilitation Robotics (ICORR) (pp. 1-6). IEEE.

Takashima, K., Rossiter, J., \& Mukai, T. (2010). McKibben artificial muscle using shape-memory polymer. Sensors and Actuators A: Physical, 164(1-2), 116-124.

Teng, T. F., Chong, S. H., Tan, M. H., Chan, C. Y., \& Sato, K. (2016). Characterization of pneumatic artificial muscle system in an opposing pair configuration. Journal of Telecommunication, Electronic and Computer Engineering (JTEC), 8(2), 73-77.

Tobushi, H., Okumura, K., Endo, M., \& Hayashi, S. (2001). Thermomechanical properties of polyurethane-shape memory polymer foam. Journal of intelligent material systems and structures, 12(4), 283-287.

Tobushi, H., Shimada, D., Hayashi, S., \& Endo, M. (2003). Shape fixity and shape recovery of polyurethane shape-memory polymer foams. Proceedings of the Institution of Mechanical Engineers, Part L: Journal of Materials: Design and Applications, 217(2), 135-143.

Veneman, J. F., Ekkelenkamp, R., Kruidhof, R., Van der Helm, F. C. T., \& van der Kooij, H. (2005, June). Design of a series elastic-and Bowden cable-based actuation system for use as torque-actuator in exoskeleton-type training. In 9th International Conference on Rehabilitation Robotics, 2005. ICORR 2005. (pp. 496-499). IEEE.
Veneman, J. F., Kruidhof, R., Hekman, E. E., Ekkelenkamp, R., Van Asseldonk, E. H., \& Van Der Kooij, H. (2007a). Design and evaluation of the LOPES exoskeleton robot for interactive gait rehabilitation. IEEE Transactions on Neural Systems and Rehabilitation Engineering, 15(3), 379-386.

Veneman, J., van Asseldonk, E., Ekkelenkamp, R., van der Helm, F., \& van der Kooij, H. (2007b, June). Evaluation of the effect on walking of balancerelated degrees of freedom in a robotic gait training device. In 2007 IEEE 10th International Conference on Rehabilitation Robotics (pp. 868-875). IEEE.

Waksman, B. (2020). Multiple sclerosis.

Wang, L., Wang, S., van Asseldonk, E. H., \& van der Kooij, H. (2013, November). Actively controlled lateral gait assistance in a lower limb exoskeleton. In 2013 IEEE/RSJ International Conference on Intelligent Robots and Systems (pp. 965-970). IEEE.

Wickramatunge, K. C., \& Leephakpreeda, T. (2010). Study on mechanical behaviors of pneumatic artificial muscle. International Journal of Engineering Science, 48(2), 188-198.

Williamson, M. M., \& Robinson, D. W. (1995). Series elastic actuators. In Proceedings IEEE International Conference on Intelligent Robots and Systems. IEEE.

Xie, T. (2010). Tunable polymer multi-shape memory effect. Nature, 464(7286), 267-270.

Yamamoto, K., Ishii, M., Noborisaka, H., \& Hyodo, K. (2004, September). Stand alone wearable power assisting suit-sensing and control systems. In ROMAN 2004. 13th IEEE International Workshop on Robot and Human Interactive Communication (IEEE Catalog No. 04TH8759) (pp. 661-666). IEEE.

Yan, T., Cempini, M., Oddo, C. M., \& Vitiello, N. (2015). Review of assistive strategies in powered lower-limb orthoses and exoskeletons. Robotics and Autonomous Systems, 64, 120-136.

Yoshimitsu, T., \& Yamamoto, K. (2004, August). Development of a power assist suit for nursing work. In SICE 2004 Annual Conference (Vol. 1, pp. 577-580). IEEE.

Zeilig, G., Weingarden, H., Zwecker, M., Dudkiewicz, I., Bloch, A., \& Esquenazi, A. (2012). Safety and tolerance of the ReWalk ${ }^{\mathrm{TM}}$ exoskeleton suit for ambulation by people with complete spinal cord injury: a pilot study. The journal of spinal cord medicine, 35(2), 96-101.

Zhang, J. F., Yang, C. J., Chen, Y., Zhang, Y., \& Dong, Y. M. (2008). Modeling and control of a curved pneumatic muscle actuator for wearable elbow exoskeleton. Mechatronics, 18(8), 448-457.

Zoss, A. B., Kazerooni, H., \& Chu, A. (2006). Biomechanical design of the Berkeley lower extremity exoskeleton (BLEEX). IEEE/ASME Transactions on mechatronics, 11(2), 128-138. 